\title{
Hidden Properties of Irish House Price Vintages
}

Using spectral analysis, prices of two Irish house vintages are investigated for hidden periodicities. What emerges is a major periodicity consistent with an Irish business cycle. A further hidden intermediate cycle in second-hand housing, that is common to all areas of Eire but featured not nearly so prominently in new housing, is posited to be related to life events and space stress.

By revisiting the housing market more often, the repeat buyer injects additional volatility in house prices. It is proposed that housing policy should be directed at reducing the number of repeat buyers as a means of deflating property bubbles.

KEY WORDS: Housing Market, New and Second-hand House Prices, Ireland, Spectral Analysis, Loss Function, Common Cycles. 


\section{Hidden Properties of Irish House Price Vintages}

\section{Introduction}

Hui (2011) divides various threads of literature about house price diffusion into three. First, the ripple effect is where house price increases in the UK appear to be led by London and the South East (Meen, 1999; Gray, 2012). Second, there is price diffusion among housing of differing qualities (Coulson and McMillen, 2007; Ho et al., 2008; Hui, 2011; Smith and Ho, 1996). The last of these three relates to distinct house price dynamics among differing sub-markets (Renaud et al., 1998). When considering a ripple through differing housing vintages, Gray (2015) suggests that Cook and Holly (2000) began a fourth. It is in this fourth strand where this work makes a contribution.

One can foresee distinctions in the market availability of new and second-hand properties. The price of a new build will be affected by monopoly practice (Barker, 2003) as well as the profitability of construction. Its supply will vary with the availability of land and construction times. The supply of second-hand properties will be related to the behaviour of owner-occupiers. To buy the next property, commonly the owner would have offer the one they currently occupy for sale.

Despite both adding to property demand, a first time buyer and a repeat buyer have differing reactions to price rises. As they are progressively priced out of a housing market, first time buyers are disadvantaged by rising prices. By contrast, ownership in a period of rising prices embeds in the value of second-hand property, and extends to the title deeds-holder, a capital gain. Stein (1995) and Ortalo-Magné and Rady (2006) argue that the capital gain fortifies the repeat buyers' purchasing power, encouraging them to participate in the market.

Although income and wealth are major factors, the motivation to consume more space is also captured by a life-events model (Clark and Davies Withers, 2009; 
Clark and Huang, 2003; Ermisch and Washbrook, 2012; Morrow-Jones and Wenning, 2005). A mismatch between the available housing space and a household's need for space is a driver to change dwellings. The demand for more space will be constrained by such factors as affordability and the down-payment (Mayer, 1993; Ortalo-Magné and Rady, 2006; Stein, 1995).

The aim of paper is to explore house price dynamics among differing vintages (new vs. second-hand) in Eire and its regions. It sets out to consider three issues. First, can new and second-hand housing dynamics be distinguished? Second, if they can be distinguished at the national level, can they be at the regional? Third, can the periodicities be related to life-events?

The paper is structured as follows. First, the volatile nature of property prices and then the influence of life-events on the motivation to move are considered. Next, relevant literature on the cyclical nature of property is discussed. The nature of the data and methodology, spectral methods and the loss function, are discussed next followed by an analysis of results.

Using data from Eire, by considering whether new and second-hand house prices have common cycles, this paper will take forward Cook and Holly (2000) and Gray $(2013 ; 2015)$. As substitutes, new and second-hand house price dynamics should be characterised by common trends and common cycles (Cook and Holly, 2000) in a cointegration sense. Arguing that the two vintages should have both common and distinct dynamics (Gray, 2015), it is concluded that some of the additional cycles are most likely a manifestation of greater turnover in second-hand markets due to lifeevents and equity that would cause volatilities at common cycles across Eire. This provides a deeper understanding of the cycles reported in Gray (2013). If life-events are combined with housing stress and financial constraints in inducing greater 
volatility, housing policy could be orientated around reducing the number of moves in housing careers.

\section{Volatility and Constraints}

As housing commonly requires a mortgage, the proportion of the price of the dwelling purchase that the buyer can secure (the loan-to-value - LTV) will be less than $100 \%$, so a deposit or down-payment is required. Stein's (1995) model of house prices and volumes focuses on this down-payment that a buyer is forced to make by lenders, in part, to filter out potential defaulters. Recognising that heightened volatility comes from the highly leveraged repeat buyer, Stein (1995) posits the prices of homes bought by those already owning a house would be more volatile than those in a starter home market, implying that second-hand prices will be more volatile than new ceteris paribus.

Stein (1995) and Ortalo-Magné and Rady (2006) argue that capital gains in the properties of credit-constrained repeat buyers fuels house price volatility. Ownership in a period of rising prices embeds in the second-hand property, and extends to the title deeds-holder, a capital gain that can be used to trade-up to a more valuable dwelling or be withdrawn as capital. Equity growth is a function of price growth. The growth rate of equity is also directly related to the LTV or inversely related to the equity-to-house value ratio. As property becomes more expensive, fortified by greater equity, more owners are willing to participate in the market. Hence, the larger the number of credit-constrained in the market, and the greater current house price inflation, with fixed a LTV criterion, the greater the access to mortgage capital and the more volatile the property price become (Ortalo-Magné and Rady, 2006; Stein, 1995). As they may foresee further price declines, a fall in price, for the owner-buyer, 
makes moving less attractive. The owner-seller, who sees a decrease in their equity needed for a future purchase or capital withdrawal, is also deterred, suggesting that the demand curve for housing could be upward sloping for some portion (Dusansky and Wilson, 1993).

A relaxation of credit constraints would exacerbate this volatility. Raising the LTV from $75 \%$ to $85 \%$ would make a given down-payment stretch to a property that is 66\% more expensive (Ortalo-Magné and Rady, 2006). Indeed, Mayer (1993) notes that Stein's (1995) model could explanation why high-priced homes might have above-average appreciation rates during housing booms, but below-average appreciation rates in a bust: high-priced, trade-up homes are more volatile over the course of the real estate cycle. In the long run though, DiPasquale and Wheaton (1996) assert that relative prices of distinct, but co-located, properties remain stable over time and are not sensitive to cyclical variations.

Ortalo-Magné and Rady (2006) concentrate on the first time buyer (FTB), the down-payment on a 'starter' dwelling and their impact on the 'trade up' home. They observe that house prices and the FTB's income are closely associated. This group is dependent on help from relatives for the down-payment but this is not true of repeatbuyers. A change in income among FTBs can lead to a price overreaction in housing for repeat-buyers, and a positive correlated between price and transactions.

Using Aberdeen housing auctions data, Thanos and White (2014) find that, in boom periods, the bid-premiums over the asking prices are notably greater than the mean distribution of bids. The investment mentality led to sustained over-bidding in the volatile 2004-2007 period, which must have been fed by relatively relaxed creditconstraints. However, the premium fell rapidly when the market turned sluggish. The collapse of the premium was not reflected immediately in asking prices, which 
respond to market conditions with a lag. Haurin, et al. (2013) also find prices in Northern Ireland tend to be more volatile in boom times, where the seller switches their pricing strategy from an asking price that sets a cap to one that is the basis for an auction. As auctions are popular in Eire (Stevenson et al., 2010) these results have an implication for Ireland: prices can be volatile.

\section{Vintages in Eire}

A simplifying assumption for distinguishing between vintages is that second-hand dwellings are put up for sale by owner [-occupiers] whilst new properties are placed on the market by builders. Owners of second-hand dwellings can join or exit the market rapidly and at low cost, adding turnover volatility to the markets when prices are already changing rapidly. Given a construction period, the builder will not be able to respond to a rise in price as quickly. Moreover, once built, the builder may need to sell the property before they can move on to the next project (Stein, 1995) possibly keeping them in the market for an extended period. Thus, the responses to prices are different.

From 1978 to quarter one 1997 the average Irish second-hand house prices was lower than that of new dwellings. Indeed, in 1978 second-hand were $20 \%$ cheaper. This could reflect a view that new houses are of higher quality, being subject to the latest building regulations and planning restrictions, technology and fashion, so commanding a higher price. Also, dwellings depreciate with time (Arnott et al., 1999). However, as new houses could be at the urban fringe and not of the same structure (DiPasquale and Wheaton 1996; Caulfield and Ahern, 2014), the second-hand average can be greater. Of course, second-hand properties may be subject to extensions and 
renovations. Benito and Power (2004) find that home improvements are a major use of housing equity release.

Barker (2003) reports that, to manage price volatility, builders in the UK restrict the supply of new builds. Glaeser et al. (2008) considers the elasticity of the supply of new housing in relation to price bubbles. They find that countries where construction is more price-sensitive tend to have shorter boom phases. However, this greater response to price leaves a larger excess stock of housing. Calera and Johansson (2013) find that, from the early 1980s to the mid 2000s by OECD standards, Ireland had a relatively high long run price elasticity in the supply of new housing. Moreover, the speed of adjustment, or supply response, is relatively rapid. Using simple algebra, Levin and Price (2009) suggest that a dramatic fall in real interest rates is likely to drive up land prices, reducing profit and the willingness to build, reducing elasticity of supply. Stevenson and Young (2014) find that developer's response disequilibrium in supply in Ireland is relatively slow. Disequilibrium in demand does not provoke a supply response at all. The insensitivity of construction output to price, Stevenson and Young (2014) conclude, can explain the prolonged Irish housing price bubble. However, the prolonged boom left a sizeable over supply, which is inconsistent with Glaeser et al. (2008).

To summarise, as they are priced out rather than in to the market, FTBs are disadvantaged by rising price, implying that their market participation declines. Also, new builds extract the capital gain that the second-hand property owner uses to tradeup. Moreover, in depressing price, the addition of new housing to the total market supply lowers the value of equity in second-hand dwellings. As such, additional supply reduces house price volatility (Stein, 1995). A market with a high proportion of repeat buyers, and hence, second-hand properties fuels price volatility (Stein, 
1995). Auctions can also add to the volatility. It is averred that the increased supply of new housing coinciding with widespread unaffordablity bursts property bubbles (Bover et al., 1989; DiPasquale and Wheaton, 1996; Pyhrr et al., 1999). As the first time buyers would have been price out of the market earlier, this unafforability is more likely to be found among the repeat buyers.

\section{Life-events and Housing}

A housing career is the sequence of housing states defined in terms of quality/characteristics of the dwelling tenure (Clark et al., 2003). This career likely to meshed with household structure and job roles. A career in the employment sense can be seen in terms of changing responsibilities and seniority over time along with the commensurate salary changes. A life course is a way of conceptualising the complex changes that are related to households. Life-events on this course would include household formation, the addition of children; their flight; and retirement. Each stage would place different household needs upon the dwelling. When the household's structure (number of members) is larger than is comfortably accommodated by the current dwelling, there is 'space-stress' (Clark and Huang, 2003): the demand for additional space is a major motivation to move. In particular, households with births and marital status alterations increase the propensity to move. One strong progenitor of space-stress is the expansion of the family unit. Clark and Davies Withers (2009) find that births are associated with the near doubling of the number of housing moves six months before, with a steady decline after. Kulu and Steele (2013) find that the timing of relocation and child-birth are linked, but one does not necessarily precede the other. Expected as well as actual space-stress could precipitate a move. Intraurban migration to large houses occurred only when the family had (many) children. 
By contrast, moves to large houses within rural areas and small towns occurred in anticipation of child-birth. Consistent with Clark and Huang (2003), housing cost and affordability are more significant factors in cities. Feijten and Mulder (2002) chart how life-events are linked to housing moves in the Netherlands. They find that there is a progression from leaving home to forming a union to buying a house and a first child for the non-singleton. Income facilitates the timing of the housing adjustment and allows the purchase a dwelling that reflects anticipated needs. Finding that mobility was not motivated by child-birth, London was distinct from the rest of the UK. This could be related to the high cost of housing in London, suggesting alleviating space-stress is a function of finance (Clark and Huang, 2003).

Using US repeat-buyers' data and a life course or life cycle perspective, Morrow-Jones and Wenning (2005) consider the 'housing ladder'. It is common for the FTB to be constrained financially and, at first purchase, be unable acquire their long term desired property. Climbing a housing ladder can be viewed as comprising a series of steps entailing a series purchases and sales that allows a buyer to acquire a dwelling of quality and price that is superior to their initial one purchased. Clark and Huang (2003) find that, up to the 50s age group, whether they are within or between tenure types, after moving, there is generally an increase in the number of rooms in the dwelling occupied by a British household: after they move, two and three person households gain space. Households are found to consume slightly more space than would be 'needed' so there is some latitude to absorb an additional member to the household. The time profile of such a pattern could be seen an inverted $U$. FernándezVillaverde and Krueger (2002) find a similar an inverted $U$ profile in long term US household expenditure patterns. Expenditure rises with age, peaking in the fifties age group and then it declines. Morrow-Jones and Wenning find that, when moving up or 
down the ladder, the age of the owner is the best explanatory variable, making age a proxy for a variety of other personal characteristics. This is consistent with a lifecycle perspective.

Ermisch and Washbrook (2012) consider the role of the down-payment or deposit as a financial constraint. A rise in price will increase the proportion of owner's equity in their property but the potential FTB will face a greater financial burden. Ermisch and Washbrook find that the potential buyers with the least and most equity in their properties are least likely to move. The former because they are probably older, have a stable familial environment, and not have children under twelve years-old. The latter would not be able to make the down-payment for obvious reasons. Greater housing equity that follows from an increase in price would raise mobility, but this would be offset by the greater cost of trading up. Relative prices among quality tiers do not alter, so price rises should not alter the timing of a move to the next housing tier.

A job change serves as a trigger for residential relocation. The most mobile group, the single renter household, is most affected by the trigger. Of any economically active household, the owner, particularly of the two-worker household, is least likely or the slowest to move (Clark and Davies Withers, 1999).

\section{Marriage and Child-birth in Eire}

Key life-events include marriages and births. The 2002 Irish Census shows that the mean age at first marriage for men and women was 32.3 and 30.3 respectively. The Hospital In-Patient Enquiry for 2002 reports that the mean age of women at birth of first child was 27.8. However, this was higher for married women (32.4), suggesting a 2.1-year gap between marriage and first born. In 2002, $40 \%$ of live births were first 
children. A further $31.2 \%$ and $17 \%$ of births were second and third children respectively. Around $64 \%$ of the children born to mothers with at least one child were within 4 years of their most recent sibling, with a median gap of just under 3 years.

\section{The Cycles in Property}

Utilising structural time series methods, Chen et al. (2004) reveal two or three hidden periodicities in house price series from Hong Kong, Singapore, Taipei and Tokyo from 1976-1998. Commonly, there is a business cycle of around 7.9 to 10.4 years, an annual cycle with a periodicity of 0.9 to 1.7 years, and an intermediate cycle in the range 3.2 to 4.4 years. They describe the business cycle as driven by exogenous shocks and the 4-year as endogenous production lag cycles. They also suggest monetary cycles also foster an over and undershooting of equilibrium. Using univariate spectral analysis, common cycles among stock indices of the property sector in Singapore, Hong Kong, Malaysia, Japan and the UK of about $2 \frac{1}{2} 2$ to 4 years are exposed by Liow (2007). Wilson and Okunev (1999) reveal high cospectra values between real estate investment trusts and financial assets markets at cycles of 3 to $3 \frac{1}{2}$ years in Australia eight in the US and six years in UK series. From this, one can deduce direct property investment is subject to effects associated with financial cycles.

Barras and Ferguson (1985) find a major cycle of 26 quarters for new orders for private housing construction, which can be distinguished from a shorter 15 quarters. Construction of new housing exhibits a merged major and minor cycle of 21 quarters. There can be more than just national cycles. Marchand (1981) reveals local cycles, defined as a set of impulses originating from industrial requirements of certain 
urban economies whose rapid, but limited impact is transmitted through import-export ties.

Using spectral analysis, Gray (2013) finds Eire and its regions have a dominant periodicity of 6.4 years in second-hand house prices. Although the regional markets are found to be integrated, Dublin, the capital, and Rural are most closely associated with the dominant cycle, whilst Cork, the second city, and Waterford are less well integrated. He finds that Waterford, Galway and Limerick have distinctive local cycles. He presumes that major and minor housing cycles are business, rather than life-cycle driven.

Cook and Holly (2000) consider whether there are common trends and cycles among old, modern and new UK house prices. Cointegration between each of the types of second-hand and new housing is found. They find that, in having its own trend, new housing is distinct. Non-synchronised, common cycles are found among the three series. This is interpreted as differential reactions to a common shock. They find that new housing is more volatile, showing a tendency to rise more rapidly and to higher peaks relative to troughs. This they put down to the ability of owners of second-hand dwellings to hold on to their properties in a downturn. These findings are at odds with the projection of greater volatility among repeat-buyers of Stein (1995) and Mayer (1993).

Again, using spectral analysis, Gray (2015) finds property vintages in the UK have distinctive dynamics. At odds with Cook and Holly (2000) who utilise the same data, he finds that new house prices are less volatility than those of either modern or older housing. All have a major cycle of $7 \frac{1}{2}$ years but there is a minor cycle of around five years' duration that is more evident in modern and older house prices than new. He links the major cycle to repeat buyers and second-hand properties whilst the minor 
cycle corresponds more with new builds and a shorter participation in the market. Although one could not see house prices being immune to such pressures, the shorter cycle is too long to reflect life-events and he instead links it with first time buyers.

\section{Methodology: Spectral Analysis}

Property cycles can be separated into endogenous and exogenous: the former because of long lead times in construction; the latter concerns the strong link between property and the wider macro-economy (Chen et al. 2004; Pugh and Dehesh, 2001). Pyhrr et al. (1999) review a large body of real estate market literature, concluding that, "the real estate literature supports the theory that real estate markets are cyclical" (p.23).

Spectral methods reveal the contribution to overall variance made at differing periodicities of a time series. These methods score over time domain analysis of common cycles as the former can be viewed as non-parametric (Kendall and Ord, 1990) so are not subject to the model misspecification problems that might affect the Granger-causal inferences made in the price diffusion field.

Spectral analysis decompose a time series into the variances associated each periodicity, ranging from the minimum of two periods, which in this case is two quarters, to the full thirty two years, plus a long run value. If a price time series has what can be described as a cycle with peaks every thirty-two quarters, the power spectrum will contain a spike at a frequency $\omega=0.03125$ rads: the larger the amplitude of the cycle, the greater the variance of the series. This variance is taken to be [house price] volatility (see appendix 1). Gray (2013) argues that the power spectrum in second-hand house prices in Eire reveals a 'carrier wave' common to all 'areas' that is consistent with its real GDP power spectrum (Levy and Dezhbakhsh, 2003). In other words, variations in national income would feed through to house 
prices. The power spectrum should also capture local cycles, associated with distinctive industrial bases (Marchand, 1981).

Dissimilarities between the profile of spikes in the spectra of new and secondhand price are assessed in two ways. Hughes-Hallett and Richter (2004) examine differences in spectra of interest rate in the tranquil pre-ERM crisis of 1992/3 with 'during' and 'after' periods. The spectral values of 'during' and 'after' are measured against the $95 \%$ confidence interval for the 'before' series at frequency $\omega_{j}$. If they fall outside, it is concluded that the power spectra values are different. A variant of that adopted here utilises the confidence intervals of both second-hand and new housing. If the lower [upper] bound of the new power spectrum $s_{N, N}(\omega)$ falls above [below] the upper [lower] bound of the second-hand $s_{2 n d, 2 n d}(\omega)$ at frequency $\omega_{j}$ the power spectral value of the new is deemed significantly above [below] the corresponding one for second-hand housing implying there is greater [smaller] levels of price volatility at that frequency.

If a second house price time series is closely associated with the first such that they are variations are associated at this thirty-two quarter cycle, this akin to covariance but at frequency $\omega=0.03125$ rads. The cospectrum corresponds with covariance but has a value associated with each periodicity. The cospectrum can be negative at a high frequency and positive at lower one, capturing divergence across short cycles but convergence at long cycles. Moreover, corresponding with the coefficient of determination $\left(R^{2}\right)$ (squared) coherence values $\left(C_{N, 2 n d}^{2}(\omega)\right)$ indicate the degrees of association of the variations in new house and second-hand prices, at each frequency. Ranging between zero and one, a low value would suggest the two vintages are not substitutes. This is unimportant if there is no spike in the power spectrum in either series at that frequency. But if one of the series has some power 
associated with this cycle, it implies that the two series can be distinguished at this frequency.

Gain can be interpreted as the regression coefficient in the time domain. The gain values are adjusted by the standard deviation of both filtered series, to generate the equivalent of a beta value in regression. The adjusted gain value is interpretation as the impact of a change of one standard deviation in house prices in to construction output, assessed in standard deviations of the latter. Deviation above[below] unity can be interpreted as implying construction is price [in]sensitive at that frequency. Price elasticity of supply is projected to be greater, the longer the cycle [period] considered.

An analytical tool, to the best of the author's knowledge, not applied in the field of house price analysis before, a loss spectrum, is an alternative method for revealing distinctive cycles in either the second-hand or new house price power spectrum. An expression for the loss spectrum is $s_{Z 2 n d}(\omega)=s_{2 n d, 2 n d}(\omega)\left(1-C_{N, 2 n d}^{2}(\omega)\right)$ (Jenkins and Watts, 1968: 437), where $s_{Z 2 n d}(\omega)$ is the loss, noise or error spectrum. In a sense, it proffers a spectrum of residuals of a two variable regression model. Where there is a spike in the power spectrum of second-hand housing but not a corresponding one in the spectrum for new house prices, the periodicity will show up as a spike in the loss spectrum. If the two power spectra are closely allied, coherence will be close to unity and there would be no spikes in the loss spectrum. A flat power or loss spectrum would imply white noise; random price changes. As Hughes-Hallett and Richter (2004) utilises two power spectra, whereas the loss spectrum is generated from coherence and a power spectrum, the two approaches are different.

A positive cospectrum value suggests that house prices move in the same direction; negative, they move in opposite directions; and around zero suggests that new and second-hand house prices are not correleted at that frequency. If they move 
in the same direction, it suggests that economic activity is driving both markets' prices and both power spectra should exhibit volatility at that periodicity. Yet the loss spectrum could still highlight differences: one spectrum could exhibit much more volatility than the other. Mayer (1993) and Smith and Tesarek (1991) anticipate higher volatility for more expensive housing. By implication, Dublin should have the highest level of volatility, particularly in second-hand housing.

If the cospectrum is negative, and new and second-hand house prices move in opposite directions, it implies buyers are switching from one to the other. What is more likely is that new housing that is released causes downward pressure on secondhand housing. It could be that builders are better placed to price properties or that repeat-buyers take longer to alter price in the face of excess supply, so there are more changes, adding to volatility. Outside of building cycles, it is difficult to explain an inverse relationship. Indeed, even the release of new property can boost second-hand prices (Ooi and Le, 2013).

If the cospectrum is around zero, signifying no co-relation, and it coincides with power in one spectrum but not the other, there should be a spike in the loss spectrum. It is evidence of distinct house price dynamics between differing vintage markets as posited by Renaud et al. (1998).

Using Eire data, Gray (2013) found local cycles in the housing spectra of second-hand series. Perhaps rather than industrial cycles, some of the shorter periodicities may be explained by life-events. It is possible that housing markets, particularly Dublin's, become divorced from local economic factors during a bubble. Moreover, where prices are exorbitant, life-events may have a smaller impact on housing (Clark and Huang, 2003). 


\section{Data $^{\mathrm{i}}$}

New and second-hand house prices data for Irish 'areas' or regions of Dublin, Cork, Galway, Limerick, Waterford and Rural plus completions and notifications to start constructing dwellings are taken from the Department of Environment, Heritage and Local Government (DoEHLG). Rural covers everywhere not captured by the urban areas listed. The quarterly data covers the period 1978Q1 to 2010Q3 for all bar notifications, which began in 2004Q1. Average house prices are mix adjusted and based on loan approval data supplied by the mortgage lending agencies.

A graphic comparison of old and new house prices with house completions in Eire and notifications made to local authorities that the builder intended to commence construction show the peak completion and house price periods occurs just after the notifications. As is partially evident from Figure 1, house prices, reported in natural logarithm form, continued to climb until around 2006.

\section{Figure 1: Prices and Quantities}

Spectral analysis is predicated on stationary data. Augmented Dickey Fuller tests for stationarity are included in appendix 2 . They show all series are difference stationary. Rather than differencing, the data in levels is detrended using the popular HodrickPrescott (H-P) filter. This entails applying a 1600 setting to the natural logarithm of price. King and Rebelo (1993) explain that the H-P filter can render any integrated process stationary of up to the fourth order. Pakko (2000) finds that the algorithm acts like a high pass filter, and is superior to differencing for spectral work. 
In Table 1, the trend element is reviewed. Over the period 1978-2010 the peak value for new houses in Eire was $€ 292,728$, achieved in the first quarter of 2007 . By contrast, second-hand prices reached $€ 345,396$ in the quarter before.

\section{Table 1. House Price Descriptors Trend}

DiPasquale and Wheaton posit that new construction would not necessarily reflect the mix of existing dwellings; it should reflect inadequacies in the current stock so that the builder can maximize profit. It takes place at the fringe of the urban area. As such, commuting to the central business district will be at its greatest, which implies it price will be the lowest for the standard house in a monocentric urban model. With rising prices more affordable, smaller housing would have been built, on the fringes of cities, such as Dublin. During the property bubble, Caulfield and Ahern (2014) find that the newer homes in Dublin are smaller and built on the fringes. This is combined with the excess supply of new housing and raised vacancy rate. Having so many new vacant properties on an estate would have a negative effect on new housing, driving the premium down.

\section{Spectral Results}

The presentation of Figure 2 is as follows: the 64 frequencies $(\omega)$ that are possible to use range from 0.0078125 to 0.5 radians, which correspond to 128 to 2 periods (quarters) plus the long-run, zero frequency. To show the relationship between the two the scaling on the horizontal axis shows both. For example, the frequency 0.0391 rads corresponds to $6.4 \mathrm{y}[\mathrm{ears}]$. Also, shorter cycles of less than a year are reported in months, such as 6.98 months (.43 rads). Greater power, volatility or covariation is revealed by a spike in the relevant spectrum. 
In Figure 2, the power spectrum of private sector completions (lefthand scale) indicates three periodicities of importance; $0.0391 \mathrm{rads}$ (6.4 years), $0.242 \mathrm{rads}$ (1year) and 0.5 rads (six months). Levy and Dezhbakhsh (2003) find a six-year periodicity within the Business Cycle zone in Irish real GDP. The one-year spike implies a seasonal effect, which would reflect a timing of a release to coincide with a house-hunting season: the data (DoELG, 2002) suggests is the summer. The sixmonth spike may reflect the time it takes to construct a dwelling.

The cospectrum of construction with both new and second-hand Eire house prices shows high positive covariation at 6.4 years, suggesting prices and quantities are pro-cyclical. When the market picks up there is more volatility in both price and quantity. What the cospectrum shows, but correlation cannot reveal, is a negative relationship between prices and quantities close to the one-year cycle and at 36 weeks. This negative relation at the one-year cycle is consistent with the release of new housing putting downward pressure on both new and second-hand housing. There seems a smaller negative effect on second-hand more than new at 36 weeks. This might be related to the gap between starts and completions, affecting expectations of future prices. There is a six-month peak in completions, which is positively related to both new and second-hand housing.

Figure 2 Private Sector Completions

The gain spectra presented in Figures 3 show a downward trend, suggesting that both second-hand and new house prices have an increasing effect on output over the longer 
run. A one standard deviation increase in new house price induces a $0.27 \times a$ one standard deviation increase in construction at the one-year cycle. This is interpreted as indicating a short term sluggish response. Prices are most influential on output at the frequencies where cospectrum values are largest, in the longer cycle range. Again this is suggesting a weak response in the short run.

Figure 3 Gain from House Prices to Construction

One would anticipate prices and quantities of new homes would be closely associated, so the cospectrum would be similar to the power spectrum. In Figures $4 \mathrm{a}$ [and $4 \mathrm{~b}$ ], the loss function (lefthand scale) of the relationship between output and second-hand [and new house] prices is displayed with the corresponding power spectrum of that series. As with the construction series, there is a key spike at longer cycles, specifically 6.4 years.

The power spectrum of new house prices shows only one large spike. In Figure $4 \mathrm{~b}$, the loss spectrum has one peak ( 6.4 years). Taking this to be the business cycle (Gray, 2013), it would suggest house price volatility is driven by income growth. As predicted by Stein (1995), market activity is pro-cyclical: prices and quantities are more volatile at the same periodicities.

Interestingly, the loss function has the same shape as the new price power spectrum. What is omitted from these but evident in the cospectrum with completions are other spikes, such as the annual and the 36-week ones. By contrast, there is one large and two smaller spikes in the loss function of Figure 4a. The one-year cycle implies seasonal effects, which are strongly evident in the completions series. There is 
a further schism in the two spectra between new and old housing. A spike that is not that evident in completions occurs at $2 \frac{1}{2}$ years, a periodicity related to second-hand market primarily.

Figure 4a Private Sector Completions with Second-hand

Figure $4 b$ Private Sector Completions with New

\section{House Price Comparisons}

There are four spectra for Eire in Figures 5a and 5c: that of the second-hand, the new prices and the corresponding cospectrum and loss spectrum associate with secondhand housing. As one would anticipate with substitutes, both old and new housing have such similar power distributions and a spike at 0.0391 rads (6.4 years). Consistent with this, there is a dominant spike in cospectrum (righthand scale). This suggests virtually all variation and covariation is focused at the business cycle in Eire.

At around $0.1016\left(2 \frac{1}{2}\right.$ years $)$ and 0.2422 (1 year) rads there are some minor cycles as well, found in the second-hand spectrum. Three spikes are evident in the loss spectrum at the frequencies highlighted so far in Figure 5c, each of about the same value. Two of these results correspond with the ones concerning completions. The loss spectrum points to a division between new and second-hand. In Figure $5 b$ 95\% upper and lower confidence thresholds of the power spectra are displayed only.

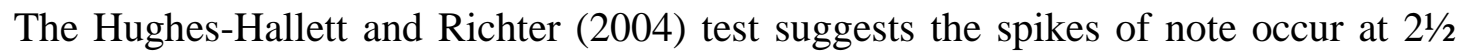
years, and 12 months only. Although the loss spectrum highlights the 6.4-year cycle, 
the confidence intervals do not suggest this is significant. What is inferred here is that second-hand price volatility is greater than new at [two] lesser periodicities, particularly the 21/2-year cycle.

Figure 5a: Power Spectra of New and $2^{\text {nd }}$ Hand Eire

Figure 5b: Power Spectra of New and $2^{\text {nd }}$ Hand Eire Confidence Intervals

Figure 5c: Cospectrum and Loss Spectra, Eire

\section{Area Analysis}

The figures in appendix 2 are displayed in a similar way to figure $5 \mathrm{~b}$, only the confidence intervals. Tables of values are also supplied. Dublin and Cork have the largest peaks in the power spectrum and the smallest in the loss spectrum. The others have smaller volatilities and greater loss spectrum values. Consistent with Mayer (1993) and Smith and Tesarek (1991), Dublin has the highest peak in the power spectrum of all the regions, which is highly concentrated at the business cycle.

If the peaks in second-hand are larger than with new housing, the thesis that former prices are more volatile than the latter would be supported. Hughes-Hallett and Richter (2004) approach failed to reveal any case where the upper confidence interval of new is below the lower confidence interval limit of the corresponding second-hand at the main cycle, as such, does not provide support for the hypothesis that secondhand house prices are more volatile than new.

The Dublin spectrum is similar to Eire's, with almost no power at anything other than the business cycle, particularly with the new housing. Second-hand price volatility is greater than new at $2 \frac{1}{2}$ years and 12 months. The loss values are very 
small compared with ones in power spectrum (only $2 \%$ at peak), and it does not show a distinct 21/2-year cycle.

Looking to other regions, the annual spike is found in the spectra of the Galway, Limerick, Waterford and Cork. Galway is unusual in that new is more volatile than second-hand. The $2 \frac{1 / 2-y e a r}{2}$ cycle is evident in all areas and power values for second-hand are greater than for new for all areas bar Limerick. Thus, this cycle is common to all areas of Ireland.

Away from the main one, spikes in the cospectra are not that notable. Other periodicities found in the loss spectrum are at the four-year (Rural) and the 17-month cycles (Waterford, Cork, Limerick, and Galway). These could be the result of local industrial cycles, or ones induced by inter-urban trade. Interestingly, most, but not all these affect both new and second-hand Irish housing but the latter vintage exhibits greater volatility. In the main, the thesis that second-hand property prices are more volatile than new is supported not at the main cycle, but at the annual and the $2 \frac{1 / 2}{2}$-year cycles.

\section{Price Issues}

Figures $4 \mathrm{~b}$ and $5 \mathrm{~b}$ show three peaks $\left(6.4,2 \frac{1}{2}\right.$ and 1 years), which broadly correspond with those of Chen et al. (2004) across four countries, and Liow (2007) across five. Thus, Eire's three peaks could be a common house price feature, internationally. However, what is novel about this study is the use of prices of both new and secondhand housing. A spike that is not that evident in the completions occurs every $2^{1 / 2}$ years, which appears to be a periodicity related to the second-hand market. As local or national economic cycles should affect both new and second-hand alike, it cannot be explained by external market factors or internal construction ones. Two possible 
explanations are considered for the driver of housing market activity; life-events and finance/ down-payments.

It was suggested in the section on Marriage and Child-birth in Eire that there is evidence of a two-year delay between marriage and first born, and under three years for subsequent children. One could envisage a first home purchase associated with marriage and a first move with the first child leading to this intermediate cycle in second-hand housing. Clark and Huang (2003) found that space-stress is not so easily relieved in the very expensive market of London. This could explain Dublin's unclear loss function pattern at the $2^{1 / 2}$-year cycle. In the Netherlands, the progression from moving into a single family dwelling to first child takes around a year: home ownership precedes the first born (Feijten and Mulder, 2002).

Having proposed this, one should note the singleton buyer, who preferred new properties, became prominent in the 2000s. This could have moderated the life-event effects on housing that would exist in more normal conditions. The singleton though, may find that household conditions change rapidly, and their new flat becomes a second-hand one for sale.

In the effervescence of a property bubble, funding ever less affordable purchases becomes a key issue. As Sun et al. (2007) report, during a 10-year Singaporean bubble phase, the equivalent $58 \%$ of the population moved home. As this is will involve rapid repeat-movers or property speculators buying and then selling in quick succession, a short cycle could emerge. As this is likely to be related to a downpayment constraint, this too could provoke an intermediate periodicity between the annual and business cycles. A relaxation of funding constraints, driven by financial markets, could make moving more feasible. There could be an injection of funds from 
financial into real estate markets, which, if cyclical, could generate intermediate property cycles (Liow, 2007; Wilson and Okunev, 1999).

\section{Supply Issues}

Barras and Ferguson reveal a cycle of 21 quarters in the construction of new housing in the UK. There is some evidence of a 41/2-year peak in Irish construction in Figure 2. Similar property cycles have been revealed in other studies. It could be that this fouryear price and output relationship reflects leakage between financial asset and real estate investment markets mentioned above.

With both gain and the cospectrum, new and second-hand housing respond in a similar way to increased supply, implying they are substitutes. The gain spectrum is interpreted as illustrating increasing price elasticity of supply with time. Although Calera and Johansson (2013) find that Irish construction is price-responsive in the long run, Stevenson and Young (2014) developers responded to disequilibrium in supply slowly. This could be related to profit being extracted from the process by the land owner (Levin and Price, 2009). The gain values in Figure 3 support the finding about price insensitivity in the short run, but over an extended period, construction is price sensitive. This combination could point to an under-supply on the short and over-supply on the long run leaving a pronounced surplus of dwellings.

\section{Conclusion}

Building on the work of Gray $(2013 ; 2015)$ and Cook and Holly (2000), it is suggested that there is an additional strand in the literature to the ones highlighted by Hui (2011); differing cycles across property vintages. The paper uses loss functions 
and power spectra to reveal differing volatilities across Irish new and second hand house prices.

The spectral methods fail to reveal hidden periodicities in new housing of Eire, Dublin and Cork, but unearth two periodicities of note, at one and 21/2-year cycles, in second-hand housing for most areas of Eire. The one-year could reflect seasonal effects. The $2 \frac{1}{2} 2$-year cycle, found across the other 'areas' of Eire, supports the common cycle thesis of Cook and Holly (2000).

Rather than concur with the conventional wisdom that it is some sort of construction cycle (Liow, 2007; Chen et al., 2004), it is averred here that this $2 \frac{1 / 2-y e a r}{}$ cycle affects mainly second-hand housing, capturing activity associated with repeatbuyers returning to the market. Life-events that lead to 'space-stress' can motivate owners to move. This is facilitated by greater equity in their exiting property.

It is not clear that Eire's second-hand housing is more volatile than new at the main cycle, undermining predictions of Stein (1995). If one focuses on other cycles and in smaller areas, there are more local features in the undulations of housing markets that suggest enhanced volatility in second-hand markets. Consistent with Mayer (1993) and Smith and Tesarek (1991), the region with the highest average prices, Dublin, has the most volatile prices, which is highly concentrated at the business cycle.

Spectral analysis exposes cycles worthy of further investigation. Some of the revealed periodicities could be local economic or building industry cycles. Most were left unexplained. There is a strong likelihood that finance, life-events and equity would cause volatilities at intermediate, common cycles across Eire and other countries. 
If forced trading up to reduce space-stress accelerates house price increases, housing policy should focus on reducing the number of moves. Diffusing the pressure to relocate and reducing the number of moves within a locale could be achieved by an increase in the number of larger properties. The construction of a large number of 'affordable' apartments for the starter market comprising singles or couples, following a life-event and the space-stress it is likely to cause, would funnel owners into repeat-buying. Inadvertently, as the space-stressed compete for a relatively smaller pool of properties at the next quality tier, a current over-supply of apartments could precipitate future heightened price volatility.

\section{References}

Arnott, R., Braid, R., Davidson, R. \& Pines, D. (1999) A General Equilibrium Spatial Model of Housing Quality and Quantity, Regional Science and Urban Economics, 99, pp. 283-316.

Barker, K. (2003) Review of Housing Supply: Interim Report - Analysis, London: HMSO.

Barras, R. \& Ferguson, D. (1985) A Spectral Analysis of Building Cycles in Britain, Environment and Planning A, 17, pp. 1369-1391.

Benito, A. and Wood, R. (2005) How Important is Housing Market Activity for Durables Spending?, Bank of England Quarterly Bulletin, Summer pp. $153-$ 159.

Bover, O., Muellbauer, J., and Murphy, A. (1989), Housing, Wages and UK Labour Markets, Oxford Bulletin of Economics and Statistics, 51, pp. 367-382. 
Caulfield, B, \& Ahern, A (2014) The Green Fields of Ireland: The Legacy of Dublin's Housing Boom and the Impact on Commuting, Case Studies on Transport Policy, in press.

Chen, M-C., Kawaguchi, Y. \& Patel, K. (2004) An Analysis of the Trends and Cyclical Behaviours of House Prices in the Asian Markets, Journal of Property Investment \& Finance, 22(1), pp. 55-75.

Clark, W. \& Davies Withers, S. (1999) Changing Jobs and Changing Houses: Mobility Outcomes of Employment Transitions, Journal of Regional Science, 39(4), pp. 653-673.

Clark, W. \& Davies Withers, S. (2009) Fertility, Mobility and Labour-ForceParticipation: a Study of Synchronicity, Population, Space and Place, 15, pp. $305-321$.

Clark, W. \& Huang, Y. (2003) The Life Course and Residential Mobility in British Housing Markets, Environment and Planning A, 35, pp. 323-339

Clark, W., Deurloo, M. \& Dieleman, F. (2003) Housing Careers in the United States, 1968-93: Modelling the Sequencing of Housing States, Urban Studies 140(1), 143-160.

Cook, S. \& Holly, S. (2000) Statistical Properties of UK House Prices: An Analysis of Disaggregated Vintages, Urban Studies, 37, pp. 2045 - 2051.

Coulson, N. \& McMillen, D. (2007) The Dynamics of Intraurban Quantile House Price Indexes, Urban Studies, 44(8), pp. 1517-1537.

CSO (2008) Construction and Housing in Ireland: 2008 Edition, Central Statistical Office, Eire: Dublin, Ireland. 
Daft.ie (2005) The Daft.ie Report: An Analysis of Recent Trends in the Irish Residential Sales Market http://c1.dmstatic.com/521/report/DaftReportQ42005.pdf accessed 10214

Dieleman, F. (2001) Modelling Residential Mobility; a Review of Recent Trends in Research, Journal of Housing and the Built Environment, 16, pp. 249-265.

DiPasquale, D. \& Wheaton, W. (1996) Urban Economics and Real Estate Markets, Englewood Cliffs, NJ, USA: Prentice Hall.

DoEHLG (2006) Annual Housing Statistics Bulletin 2006, Department of the Environment and Local Government: Stationary Office, Dublin http://www.cso.ie/px/Doehlg/Database/DoEHLG/Housing\%20Statistics/Housi ng\%20Statistics.asp, accessed 1313 .

DoELG (2002) Annual Housing Statistics Bulletin 2002, Department of the Environment and Local Government: Stationary Office, Dublin

Dusansky, R. \& Wilson, R. (1993) The Demand for Housing: Theoretical Considerations, Journal of Economic Theory, 61, pp.120-38.

Ermisch, J. \& Washbrook, E. (2012) Residential Mobility: Wealth, Demographic and Housing Market Effects. Scottish Journal of Political Economy, 59, pp. 483499.

Fernández-Villaverde, J. \& Krueger, D. (2002) Consumption over the Life Cycle: Some Facts from the Consumer Expenditure Survey Data. NBER Working Paper 9382 http://www.nber.org/papers/w9382 accessed 11214.

Feijten, P. \& Mulder, C. (2002) The Timing of Household and Housing Events in the Netherlands: A Longitudinal Perspective, Housing Studies, 17(5), pp. 773792. 
Glaeser, E., Gyourko, J. \& Saiz, A. (2008) Housing Supply and Housing Bubbles, Journal of Urban Economics, 64(2), pp. 198-217.

Gray, D. (2012) District House Price Movements in England and Wales 1997-2007: An Exploratory Spatial Data Analysis Approach, Urban Studies, 49(7), pp. $1411-1434$.

Gray, D. (2013) House Price Diffusion: An Application of Spectral Analysis to the Prices of Irish Second-Hand Dwellings, Housing Studies, 28(6), pp. 869-890.

Gray, D. (2015) Are Prices of New Dwellings Different? A Spectral Analysis of UK Property Vintages, Cogent Economics and Finance, 3.

Hamilton, J. (1994) Time Series Analysis, Princeton, New Jersey, USA: Princeton University Press.

Haurin, D., McGreal, S., Adair, A., Brown, L. \& Webb, J. (2013) List Price and Sales Prices of Residential Properties during Booms and Busts, Journal of Housing Economics, 22, pp. 1-10.

Ho, L., Ma, Y. \& Haurin, D. (2008) House Price Changes Across Quality Tiers, Journal of Real Estate Finance \& Economics, 37(4), pp. 299-316.

Hospital In-Patient Enquiry for 2002 (2006) National Perinatal Reporting System, The Economic \& Social Research Institute, Eire.

Housing Market Overview

http://www.cso.ie/px/Doehlg/Database/DoEHLG/Housing\%20Statistics/Housi ng\%20Statistics.asp, Department of Environment, Heritage and Local Government, Eire, accessed 1313.

Hughes-Hallett, A. \& Richter, C. (2004) Spectral Analysis as a Tool for Financial Policy: An Analysis of the Short-End of the British Term Structure, Computational Economics, 23(3), pp. 271-288. 
Hui, H-C. (2011) Cycles in Landed and Non-Landed Housing Sub-Markets in Malaysia, International Journal of Housing Markets and Analysis, 4(2), pp. $144-154$.

Jenkins, G. \& Watts, D. (1968) Spectral Analysis and Its Applications, London: Holden-Day.

Kendall, M. \& Ord, K. (1990) Time Series, $3^{\text {rd }}$ ed., New York: Wiley.

King, R. \& Rebelo, S. (1993) Low Frequency Filtering and Real Business-Cycles, Journal of Economic Dynamics and Control, 17, pp. 207-31.

Kulu, H. \& Steele, F. (2013) Interrelationships Between Childbearing and Housing Transitions in the Family Life Course, Housing Studies, 50(5), pp. 1687-1714.

Levin, E. \& Price, G. (2009) What Determines the Price Elasticity of House Supply? Real Interest Rate Effects and Cyclical Asymmetries, Housing Studies, 24(6), pp. 713-736.

Levy, D. \& Dezhbakhshb, H. (2003) International Evidence on Output Fluctuation and Shock Persistence, Journal of Monetary Economics, 50, pp. 1499-1530.

Liow, K. (2007) Cycles and Common Cycles in Real Estate Markets, International Journal of Managerial Finance, 3(3), pp. 287-305.

Marchand, C. (1981) Maximum Entropy Spectra and the Spatial and Temporal Dimensions of Economic Fluctuations in an Urban System, Geographical Analysis, 13(2), pp. 95-116.

Mayer, C. (1993) Taxes, Income Distribution, and the Real Estate Cycle: Why All Houses Do Not Appreciate at the Same Rate, New England Economic Review, May June, pp.39-50. 
McGough, T. \& Tsolacos, S. (1995) Property Cycles in the UK: an Empirical Investigation of the Stylized Facts, Journal of Property Finance, 6(4), pp. 4562.

Meen, G. (1999) Regional House Prices and the Ripple Effect: A New Interpretation, Housing Studies, 14(6), pp. 733-753.

Morrow-Jones, H. \& Wenning, M. (2005) The Housing Ladder, the Housing LifeCycle and the Housing Life-Course: Upward and Downward Movement among Repeat Home-Buyers in a US Metropolitan Housing Market, Urban Studies, 42(10), pp.1739-1754.

Ooi, J, \& Le, T. (2013) The spillover effects of infill developments on local housing prices, Regional Science and Urban Economics, 43(6), pp. 850-861.

Ortalo-Magné, F. \& Rady, S. (2006) Housing Market Dynamics: On the Contribution of Income Shocks and Credit Constraints, Review of Economic Studies, 73(2), pp. $459-485$.

Pakko, M. (2000) The Cyclical Relationship between Output and Prices: An analysis in the Frequency Domain, Journal of Money Credit and Banking, 32(3), pp. 382-399.

Pugh, C. \& Dehesh, A. (2001) Theory and Explanation in International Property Cycles since 1980, Property Management, 19(4), pp. 265-297.

Pyhrr, S., Roulac, S. \& Born, W. (1999) Real Estate Cycles and their Strategic Implications for Investors and Portfolio Managers in the Global Economy, The Journal of Real Estate Research, 18(1), pp. 7-68.

Renaud, B., Zhang, M. \& Koeberle, S. (1998) How the Thai real Estate Boom Undid Financial Institutions - What can be done now? Conference on Thailand's Dynamic Economic Recovery and Competitiveness 2051998 Bangkok 
http://citeseerx.ist.psu.edu/viewdoc/download;jsessionid=E314B03D2C9B39

\section{$\underline{\text { A31AAC1582D7EFFD40?doi=10.1.1.196.1373\&rep=rep1\&type=pdf }}$}

(accessed 12214$)$

Smith, B. \& Tesarek W. (1991) House Prices and Regional Real Estate Cycles: Market Adjustments in Houston, Real Estate Economics, 19(3), pp. 396-416

Smith, L. \& Ho, M. (1996) The Relative Price Differential between Higher and Lower Priced Homes, Journal of Housing Economics, 5, pp. 1-17.

Stein, J. (1995) Prices and Trading Volume in the Housing Market: a Model with Downpayment Effects, The Quarterly Journal of Economics 110, pp. 379405.

Stevenson, S. \& Young, J. (2014) A Multiple Error-Correction Model of Housing Supply, Housing Studies, 29(3), pp. 362-379.

Stevenson, S., Young, J. \& Gurdgiev, C. (2010) A Comparison of the Appraisal Process for Auctions and Private Treaty Residential Sales, Journal of Housing Economics, 19(2), pp. 145-154.

Sun, J., Sim, L-L. \& Ho, K. (2007) The Cyclical Association of Residential Price and Consumption, Journal of Real Estate Portfolio Management, 13(3), pp. 219248.

Thanos, S. \& White, M. (2014) Expectation Adjustment in the Housing Market: Insights from the Auction System in Scotland, Housing Studies, 29(3), pp. 339-361.

Wilson, P. \& Okunev, J. (1999) Spectral Analysis of Real Estate and Financial Assets Markets, Journal of Property Investment and Finance, 17(1), pp. 61-74. 


\section{Appendix 1}

\section{Spectral Methods}

The theoretical spectrum divides up a time series into a set of components that are orthogonal. It reveals the relative power at each frequency corresponding to the variance at each periodicity, so that sharp peaks denote a high concentration. The auto-covariance $\gamma_{X X}(k)=E\left[\left(X_{t+k}-\mu\right)\left(X_{t}-\mu\right)\right]$ in the time domain is represented as $s_{X X}(\omega)=\frac{1}{2 \pi} \sum_{k=-\infty}^{\infty} \gamma_{X X}(k) e^{-i k \omega}$ in the frequency domain. As the periodogram does not provide a consistent estimate of the theoretical spectrum, smoothing is required. There is a trade-off between stability and fidelity. The power spectrum is given by $\hat{s}_{X X}(\omega)=\frac{1}{2 \pi} \sum_{k=-M}^{M} w(k) \hat{\gamma}_{X X}(k) e^{-i \omega k}$. The $95 \%$ confidence band for the spectrum with $v=$ Equivalent Degrees of Freedom is given by $\hat{s}_{X X}(\omega)(1 \pm 1.96 \sqrt{2 / v})^{-1}$. The corresponding expression of the cross spectrum, $\hat{s}_{X Y}(\omega)=\frac{1}{2 \pi} \sum_{k=-M}^{M} w(k) \hat{\gamma}_{X Y}(k) e^{-i \omega k}$, can be broken down into the real and imaginary parts, $s_{X Y}(\omega)=c_{X Y}(\omega)-i q_{X Y}(\omega)$, where the cospectrum is defined as $c_{X Y}(\omega)=\frac{1}{2 \pi} \sum_{k=-\infty}^{\infty} \gamma_{X Y}(k) \cos (\omega k)$. The cospectrum between $X$ and $Y$ at frequency $\omega_{j}$ represents the covariance between $X$ and $Y$ at frequency $\omega_{j}$ (Hamilton, 1994). Gain 1 is given by $G_{X Y}(\omega)=\frac{\left|s_{X Y}(\omega)\right|}{s_{X}(\omega)}$. Gain is the equivalent of a regression coefficient in the time domain but at given frequencies. In this case Gain $1 G_{C N}\left(\omega_{j}\right)$, identifies how the amplitude of output is translated into the amplitude of house price cycles in $\operatorname{HP}_{N}(\omega)$ at frequency $\omega_{j}$ (Sun et al., 2007). Gain 2, $G_{N C}\left(\omega_{j}\right)$, involves the reverse. Only Gain2 is utilised. Coherence is the frequency 
domain equivalent of squared correlation. If the coherence is large, it indicates the degree to which $X$ and $Y$ are jointly influenced at a common frequency $\omega_{j}$. The estimated squared coherence is given by $\hat{C}_{X Y}{ }^{2}\left(\omega_{j}\right)=\frac{\left|\hat{s}_{X Y}\left(\omega_{j}\right)\right|^{2}}{\hat{s}_{X}\left(\omega_{j}\right) \hat{s}_{Y}\left(\omega_{j}\right)} \quad$ (Jenkins and Watts, 1968).

$T=128$ with smoothing across 3 points with a Parzen lag window, where $v$ is the number of degrees of freedom $(=158)$.

Augmented Dickey Fuller Tests

ADF test involves an autoregressive model of order $p$. Step one involves the estimation of equation

$$
\Delta x_{t}=\alpha+(\rho-1) x_{t-1}+\beta t+\sum_{j=1}^{p} \alpha_{j} \Delta x_{t-j}+\varepsilon_{t}
$$

where

$p$ is the order of the lag polynomial

$\varepsilon_{t} \sim \operatorname{iid}\left(0, \sigma_{\varepsilon}^{2}\right)$

$t$ is a time trend.

A second version entails the reestimation without the time trend. As the data is reported on a quarterly basis $p$ is set to 4 .

\section{Appendix 2}

Table a1 Augmented Dickey Fuller Tests

Table a2 Power Spectra with 95\% confidence interval limits: Eire

Figure a1: Power Spectra of New and $2^{\text {nd }}$ Hand, Dublin

Figure a2: Cospectrum and Loss Spectra, Dublin

Table a3 Power Spectra with 95\% confidence interval limits: Dublin 
Figure a3 Power Spectra of New and $2^{\text {nd }}$ Hand, Rural

Figure a4: Cospectrum and Loss Spectra, Rural

Table a4 Power Spectra with 95\% confidence interval limits: Rural

Figure a5: Power Spectra of New and $2^{\text {nd }}$ Hand, Cork

Figure a6: Cospectrum and Loss Spectra, Cork

Table a5 Power Spectra with 95\% confidence interval limits: Cork

Figure a7: Power Spectra of New and $2^{\text {nd }}$ Hand, Limerick

Figure a8: Cospectrum and Loss Spectra, Limerick

Table a6 Power Spectra with 95\% confidence interval limits: Limerick

Figure a9: Power Spectra of New and $2^{\text {nd }}$ Hand, Galway

Figure a10: Cospectrum and Loss Spectra, Galway

Table a7 Power Spectra with 95\% confidence interval limits: Galway

Figure a11: Power Spectra of New and $2^{\text {nd }}$ Hand, Waterford

Figure a12: Cospectrum and Loss Spectra, Waterford

Table a8 Power Spectra with 95\% confidence interval limits: Waterford 


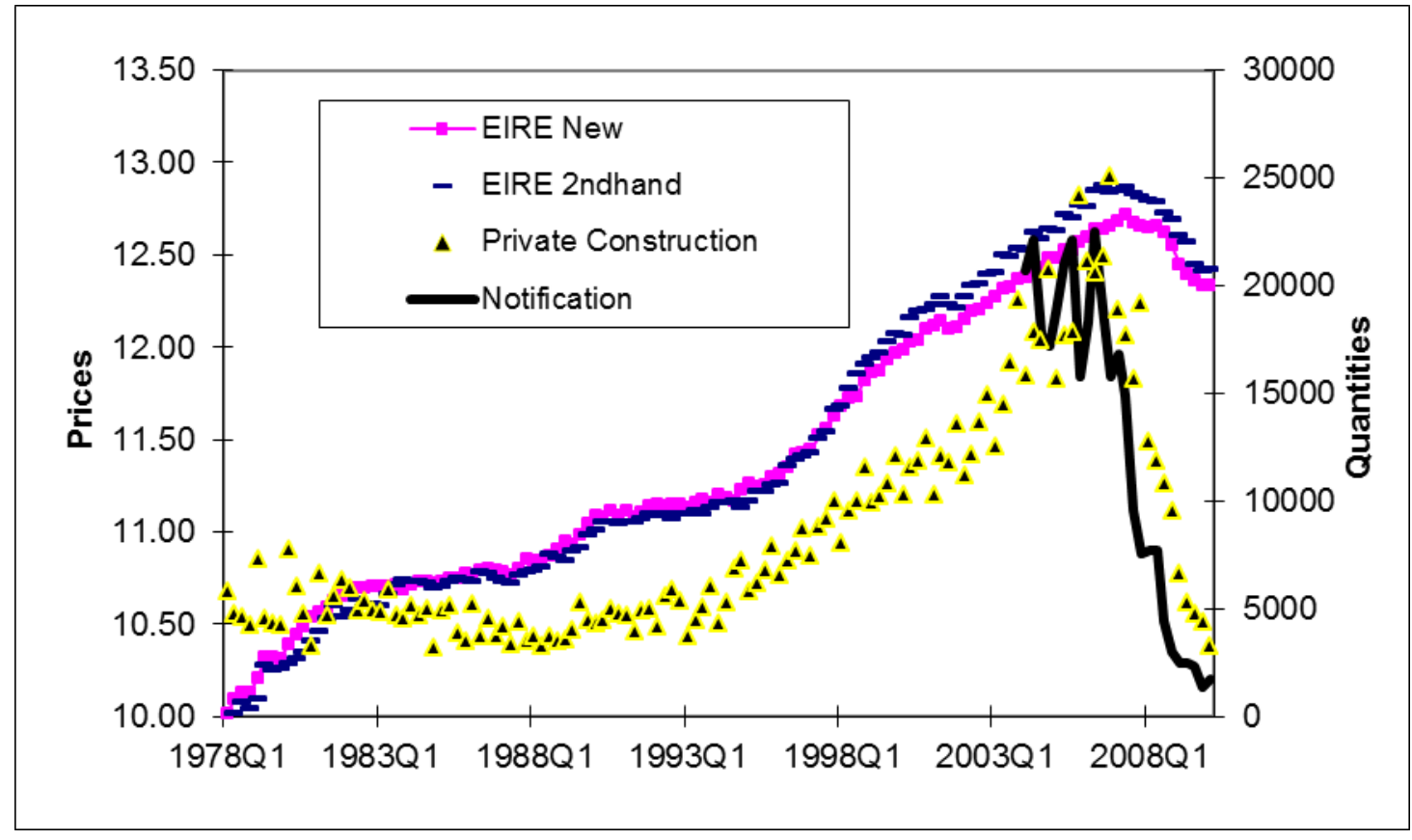

Figure 1: Prices and Quantities 


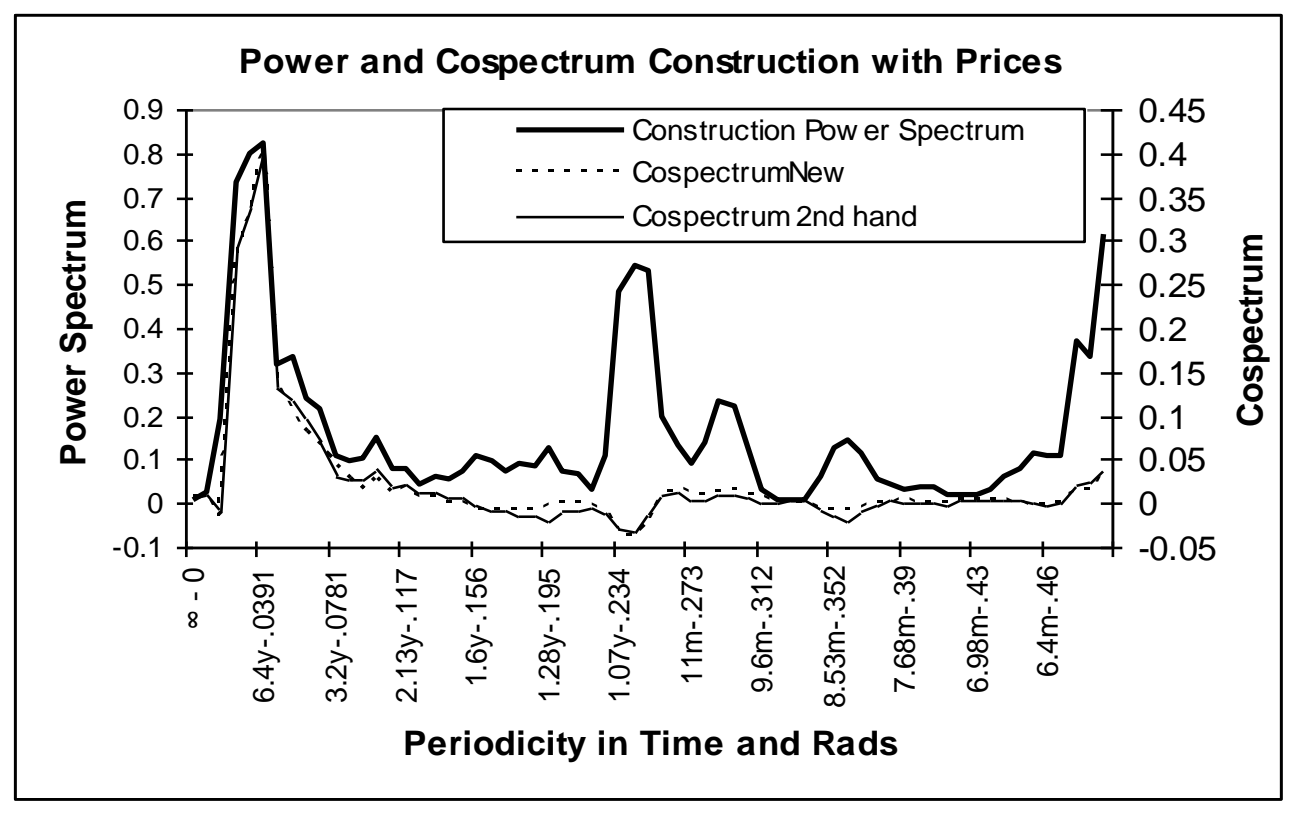

Figure 2 Private Sector Completions 


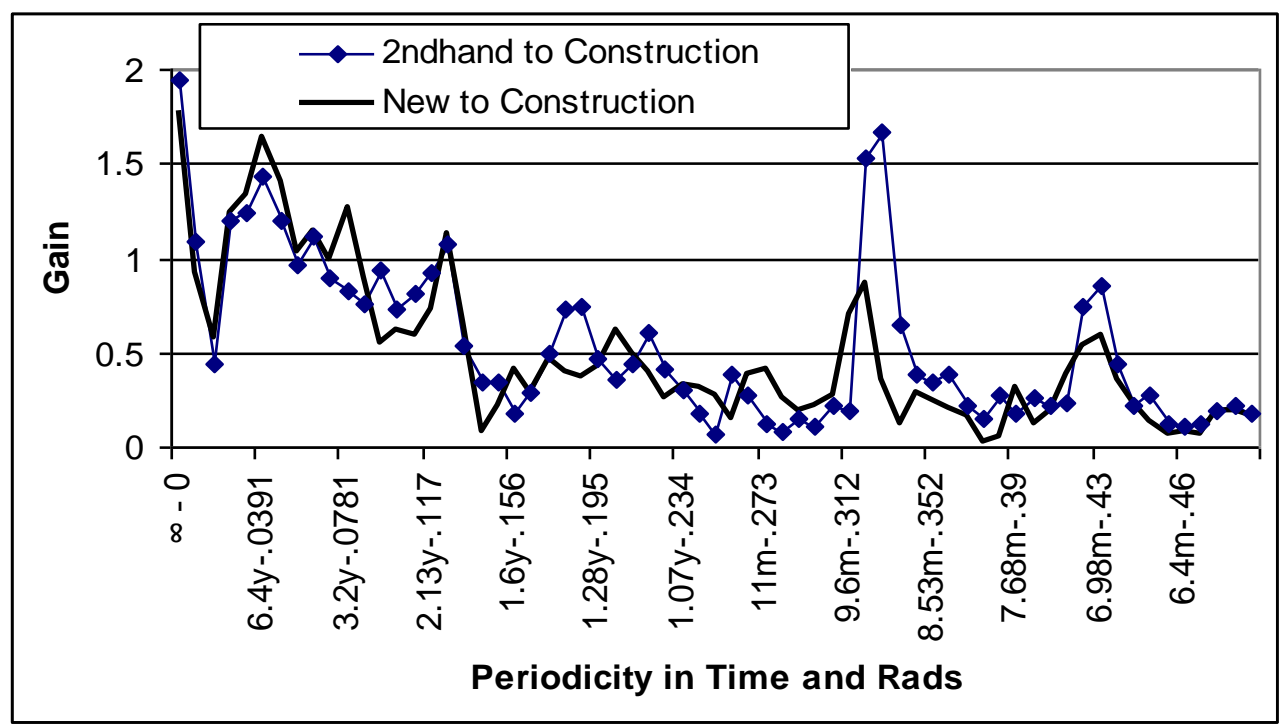

Figure 3 Gain from House Prices to Construction 


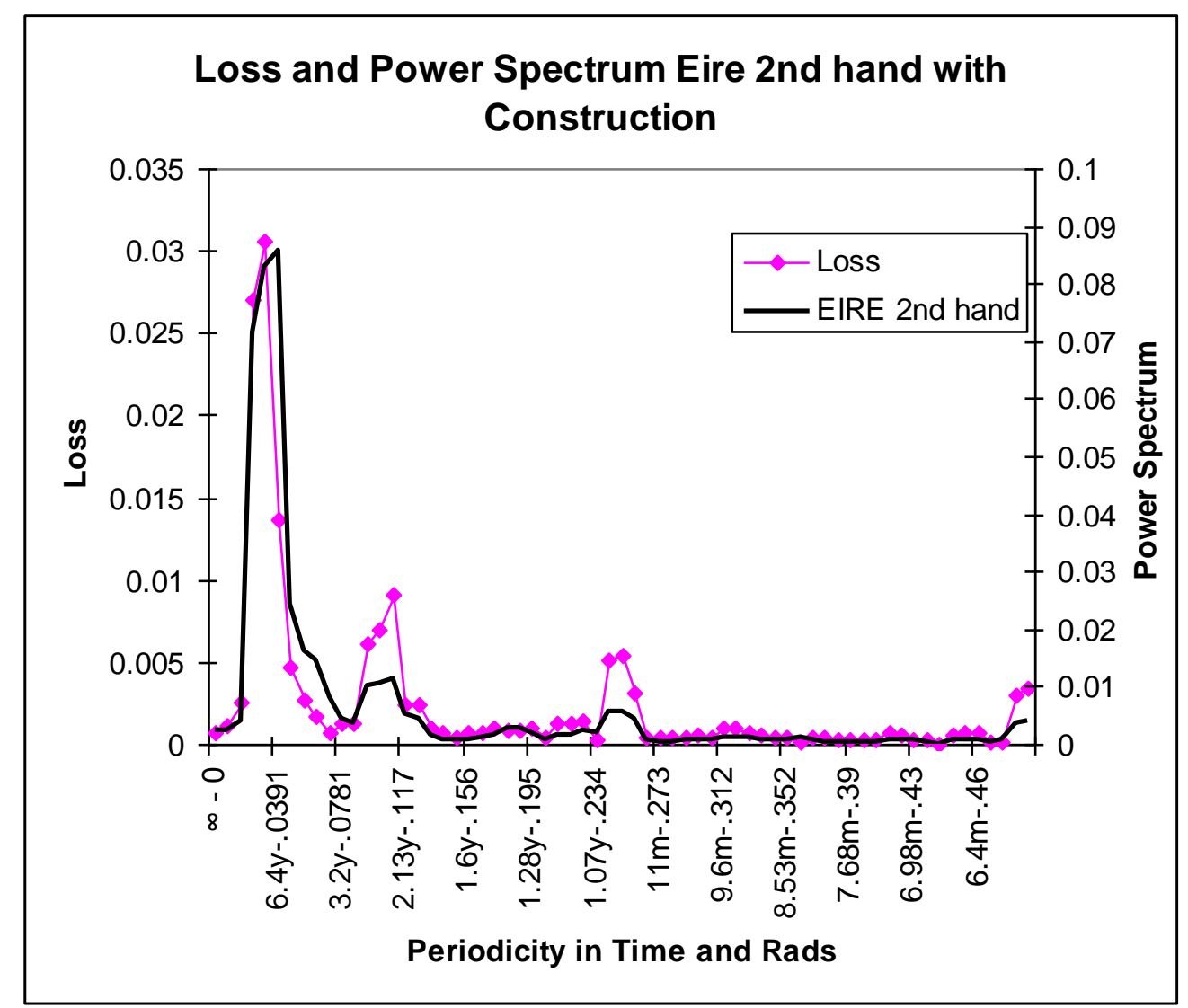

Figure 4a Private Sector Completions with Second-hand 


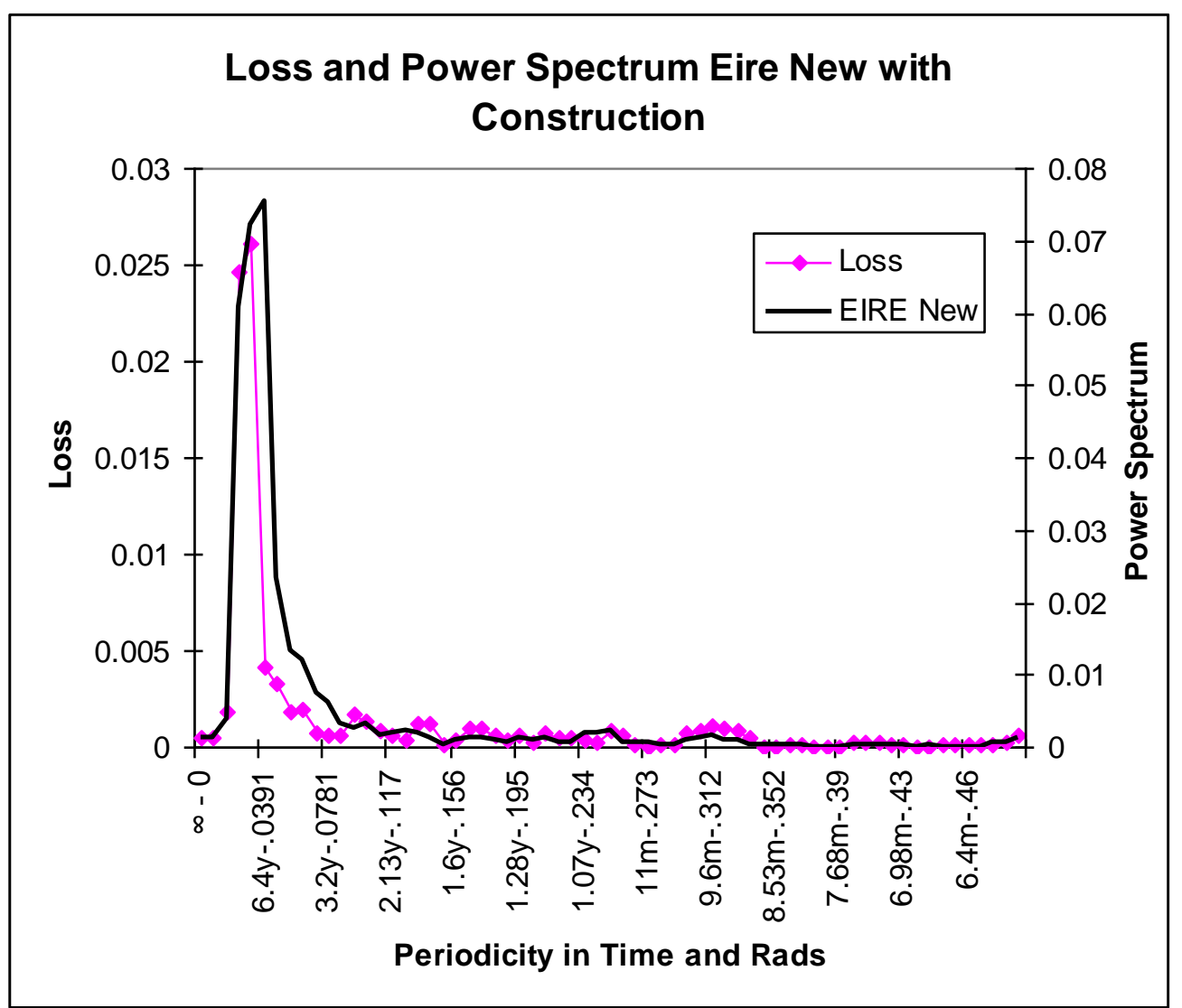

Figure $4 b$ Private Sector Completions with New 


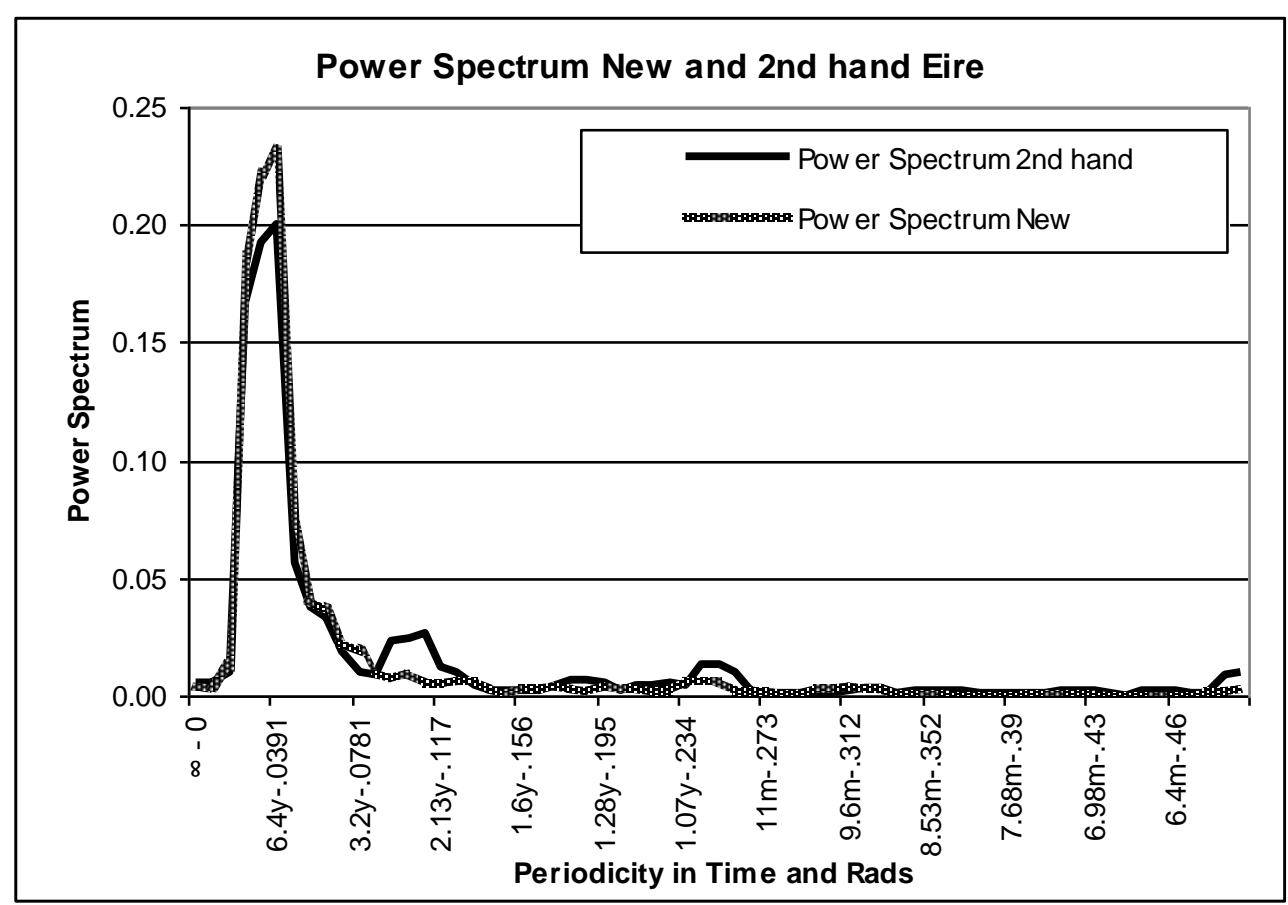

Figure 5a: Power Spectra of New and $2^{\text {nd }}$ Hand Eire 


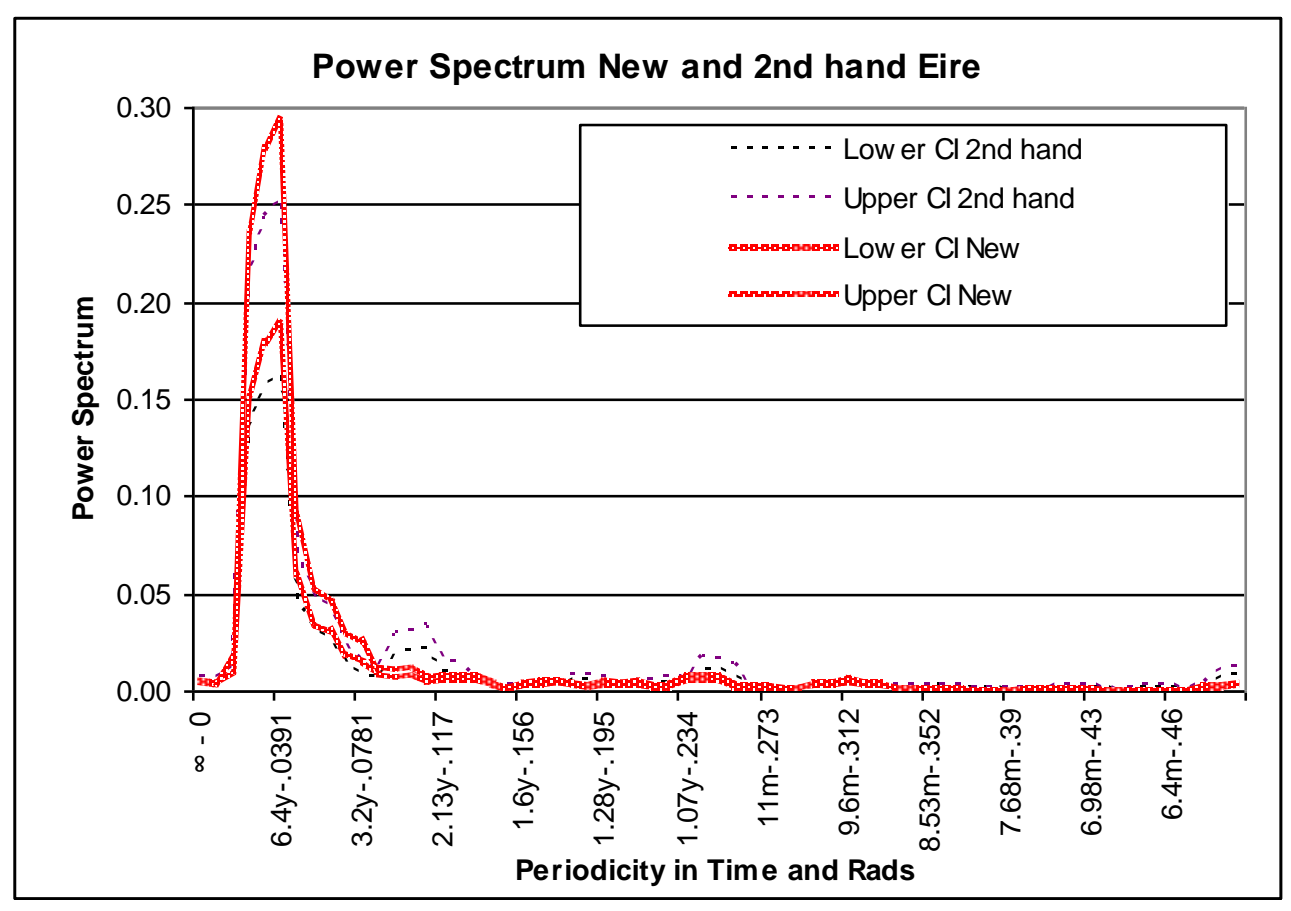

Figure 5b: Confidence Intervals of the Power Spectra of New and $2^{\text {nd }}$ hand, Eire 


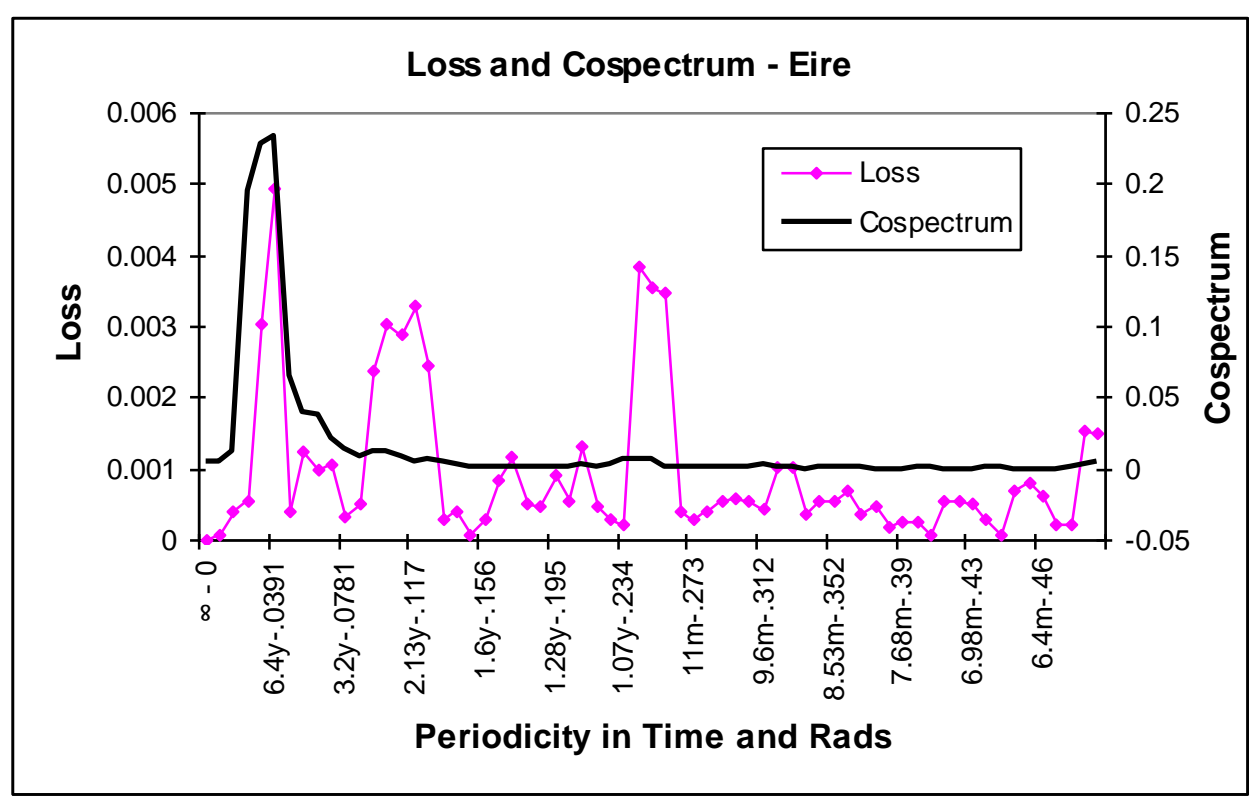

Figure 5c: Cospectrum and Loss Spectra, Eire 


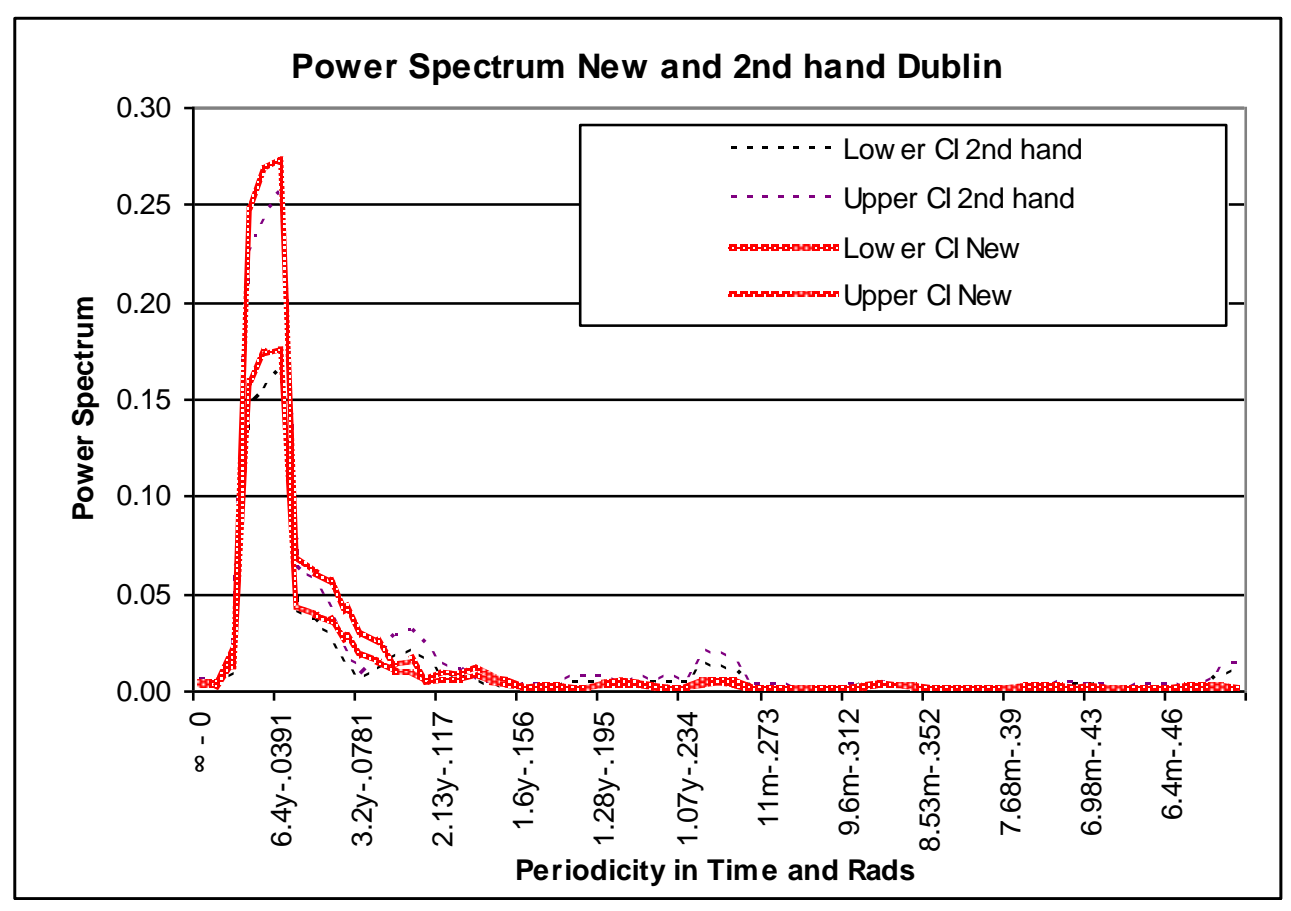

Figure a1: Confidence Intervals of the Power Spectra of New and $2^{\text {nd }}$ hand, Dublin 


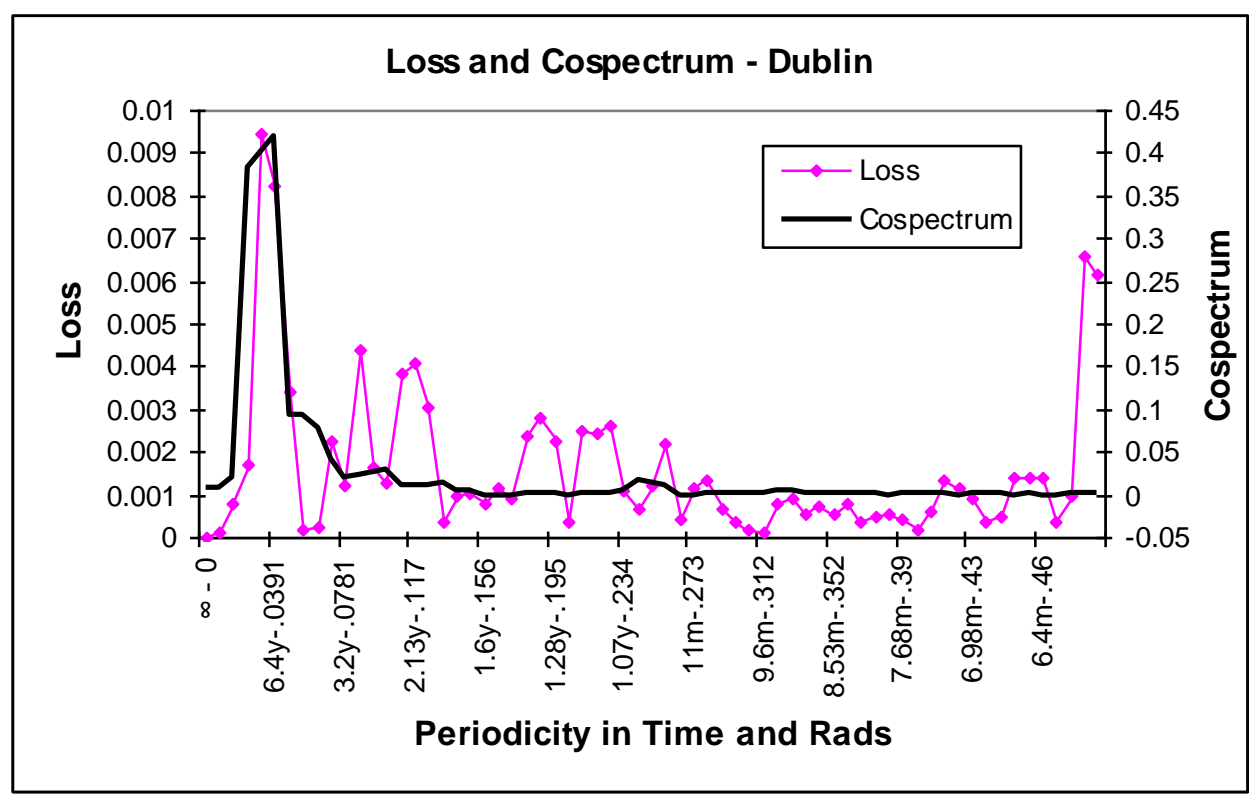

Figure a2: Cospectrum and Loss Spectra, Dublin 


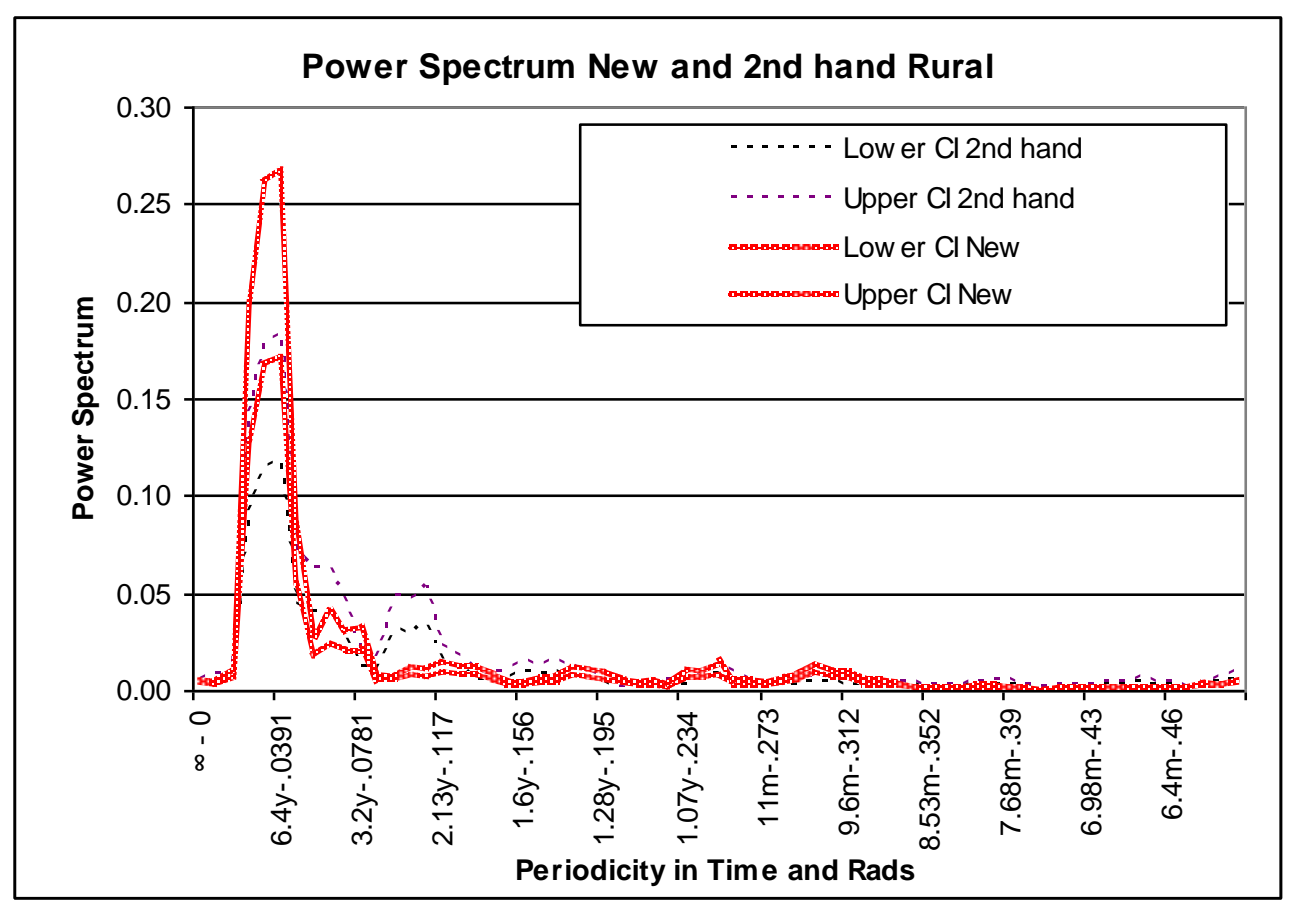

Figure a3 Confidence Intervals of the Power Spectra of New and $2^{\text {nd }}$ hand, Rural 


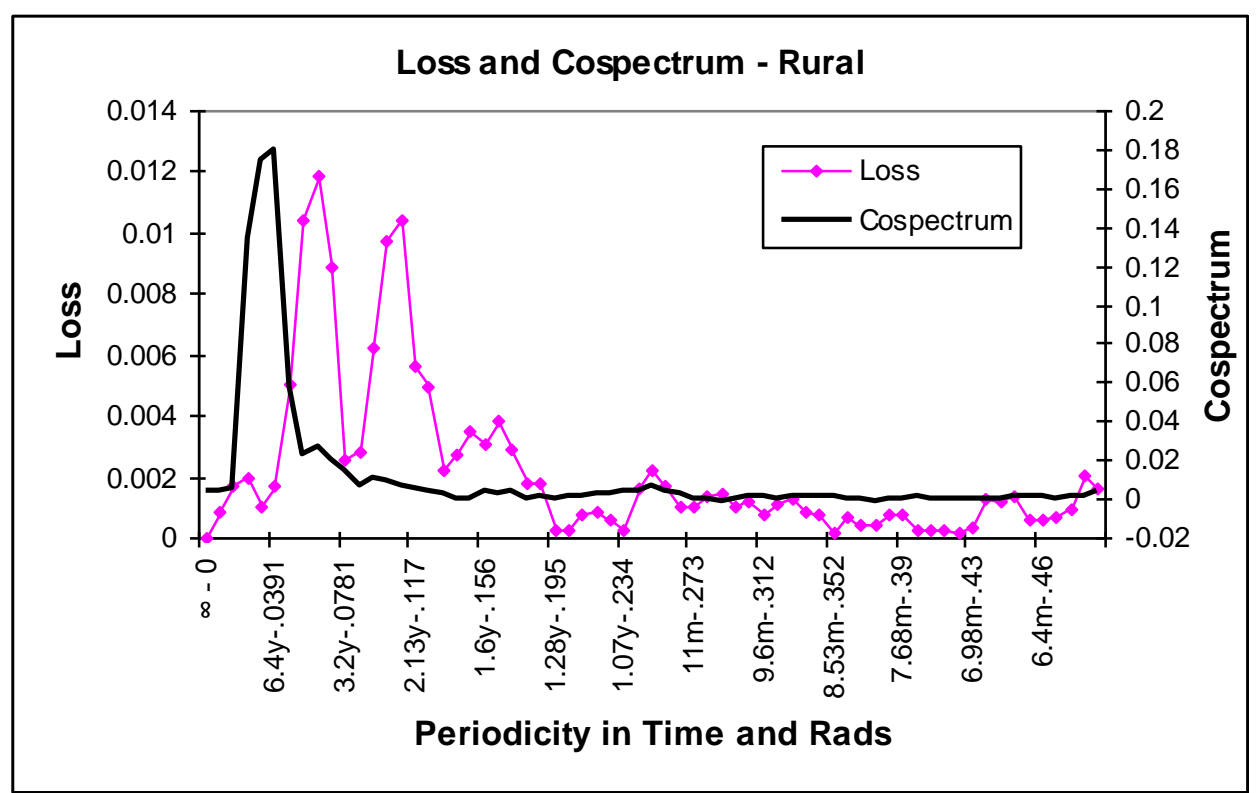

Figure a4: Cospectrum and Loss Spectra, Rural 


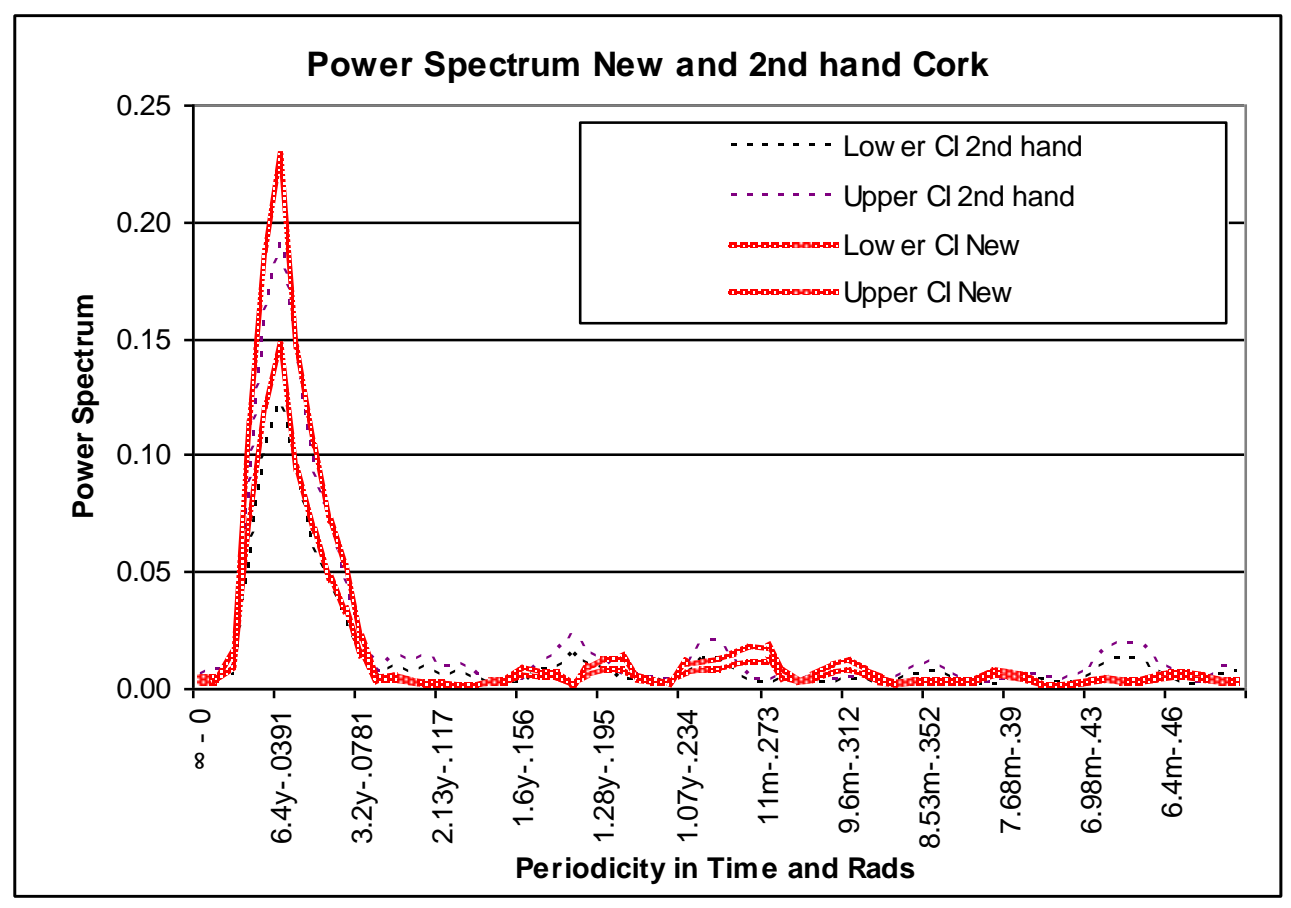

Figure a5: Confidence Intervals of the Power Spectra of New and $2^{\text {nd }}$ hand, Cork 


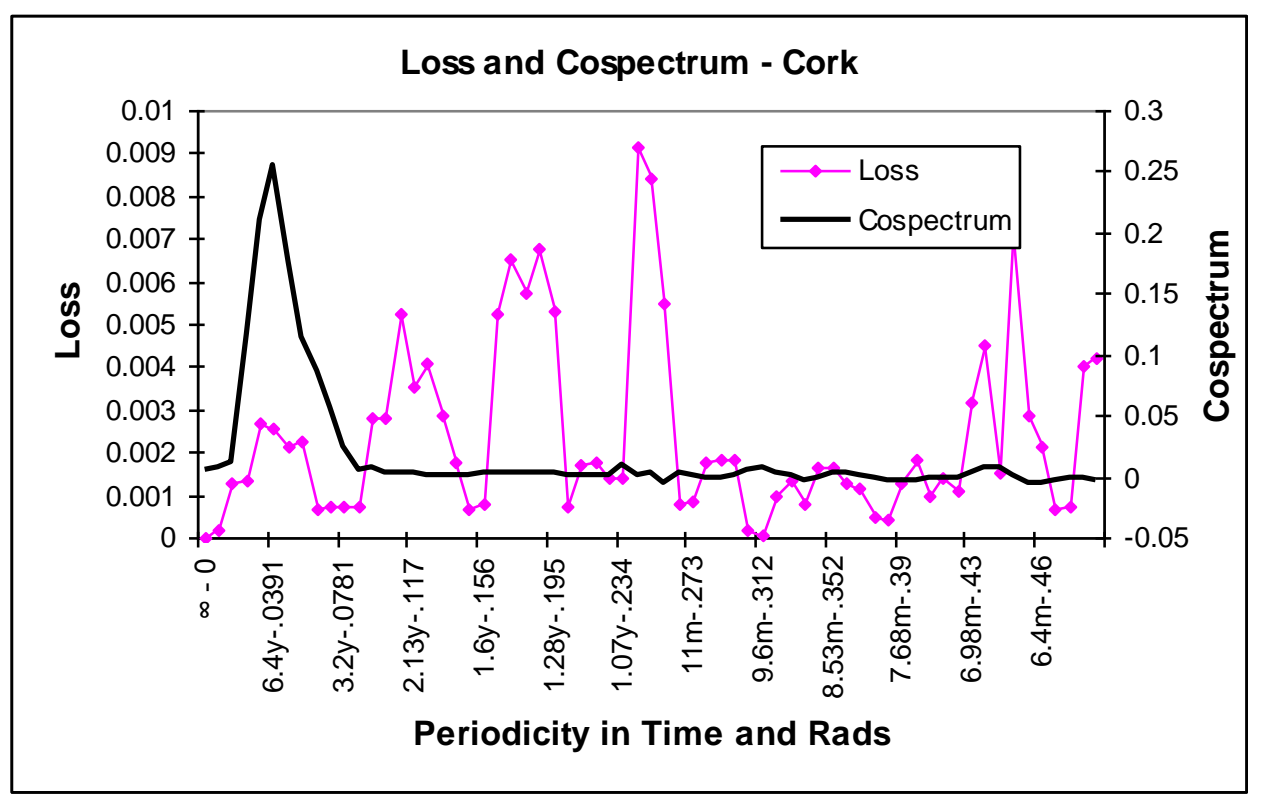

Figure a6: Cospectrum and Loss Spectra, Cork 


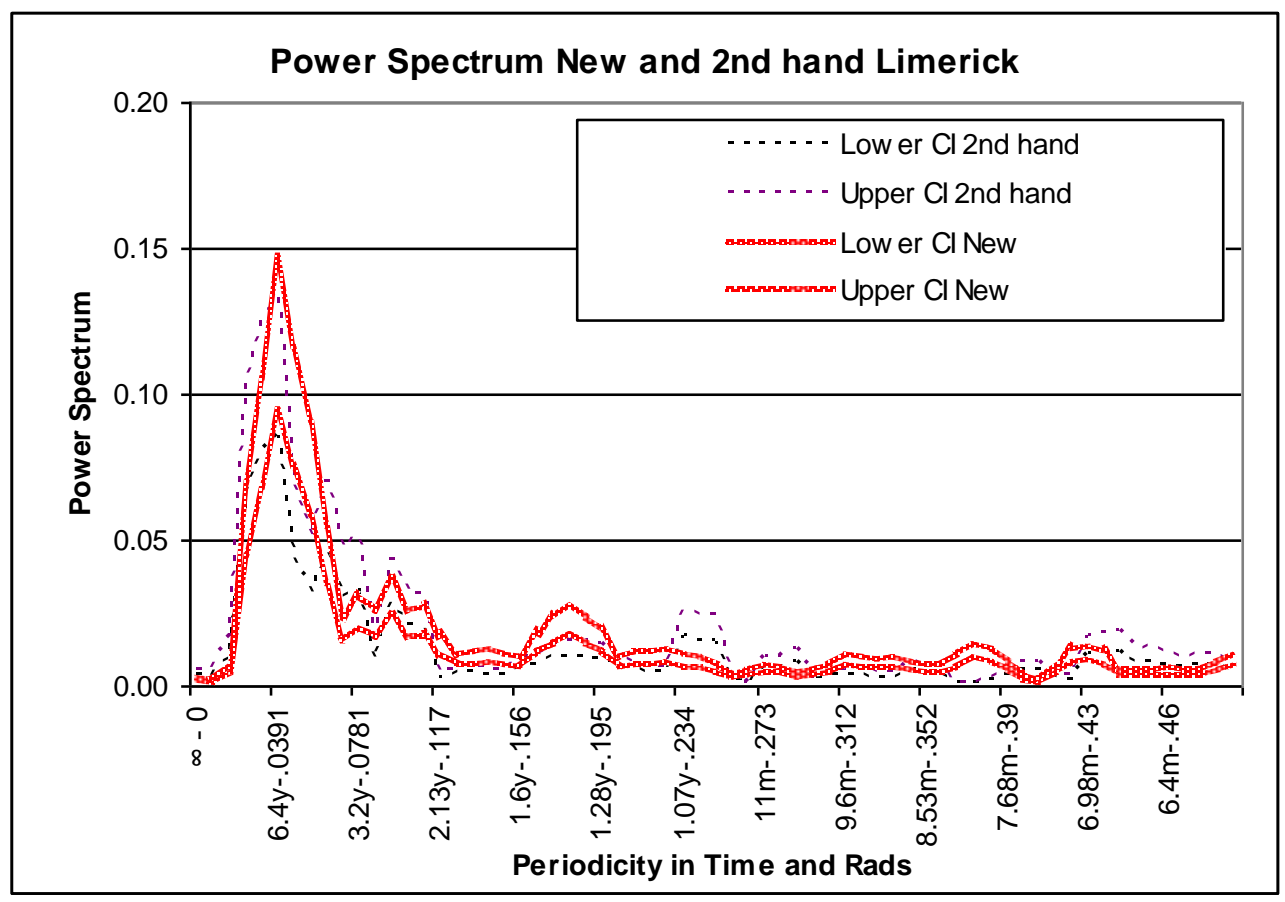

Figure a7: Confidence Intervals of the Power Spectra of New and $2^{\text {nd }}$ hand, Limerick 


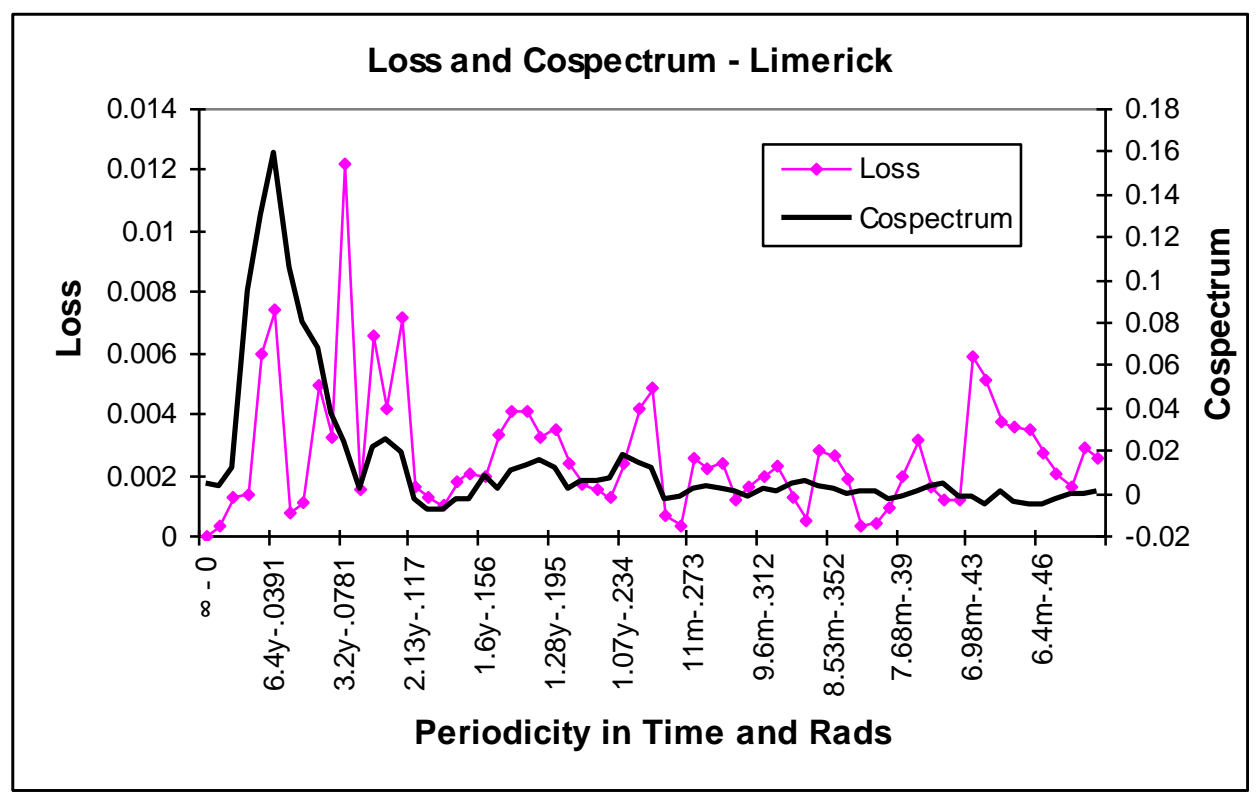

Figure a8: Cospectrum and Loss Spectra, Limerick 


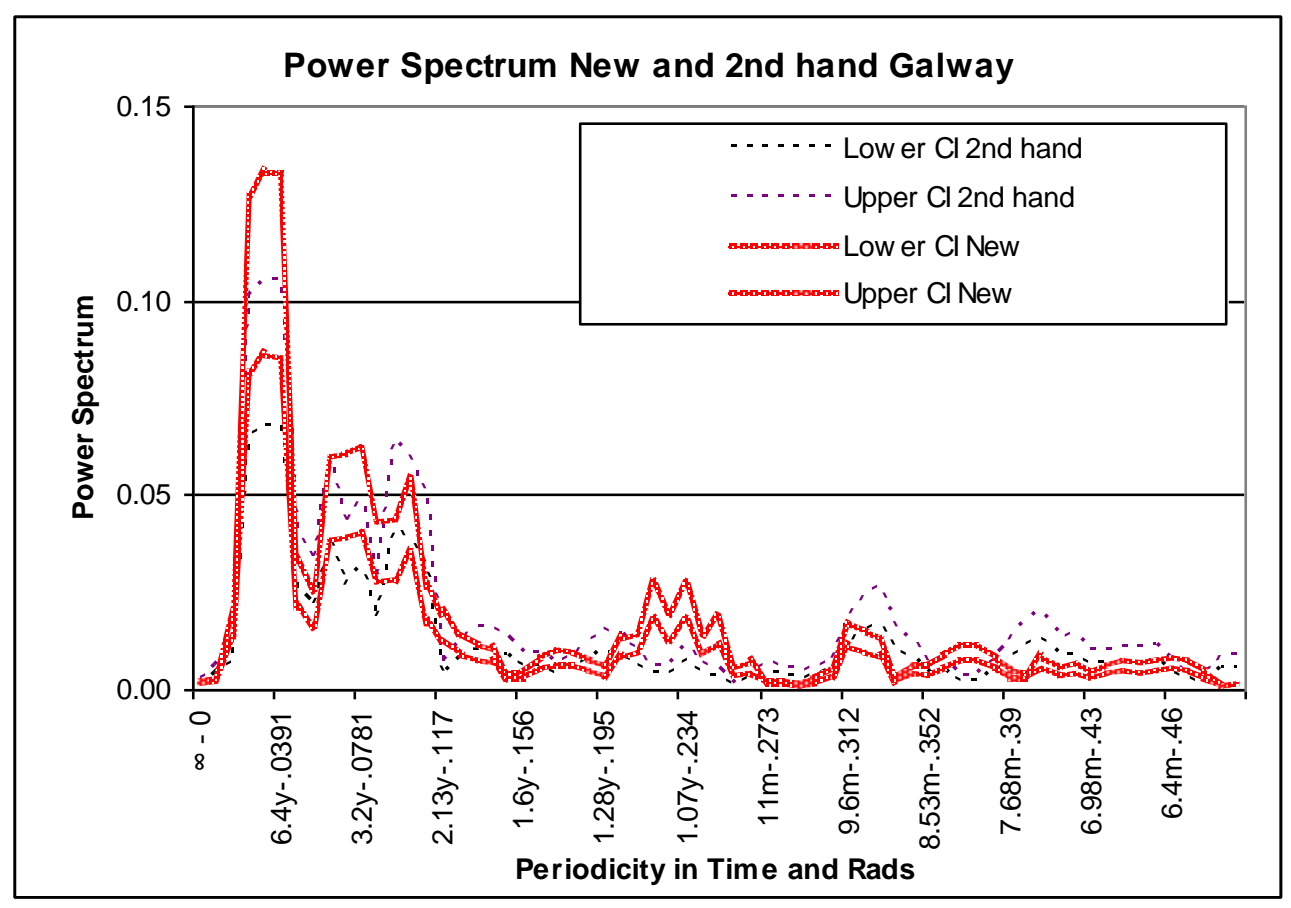

Figure a9: Confidence Intervals of the Power Spectra of New and $2^{\text {nd }}$ hand, Galway 


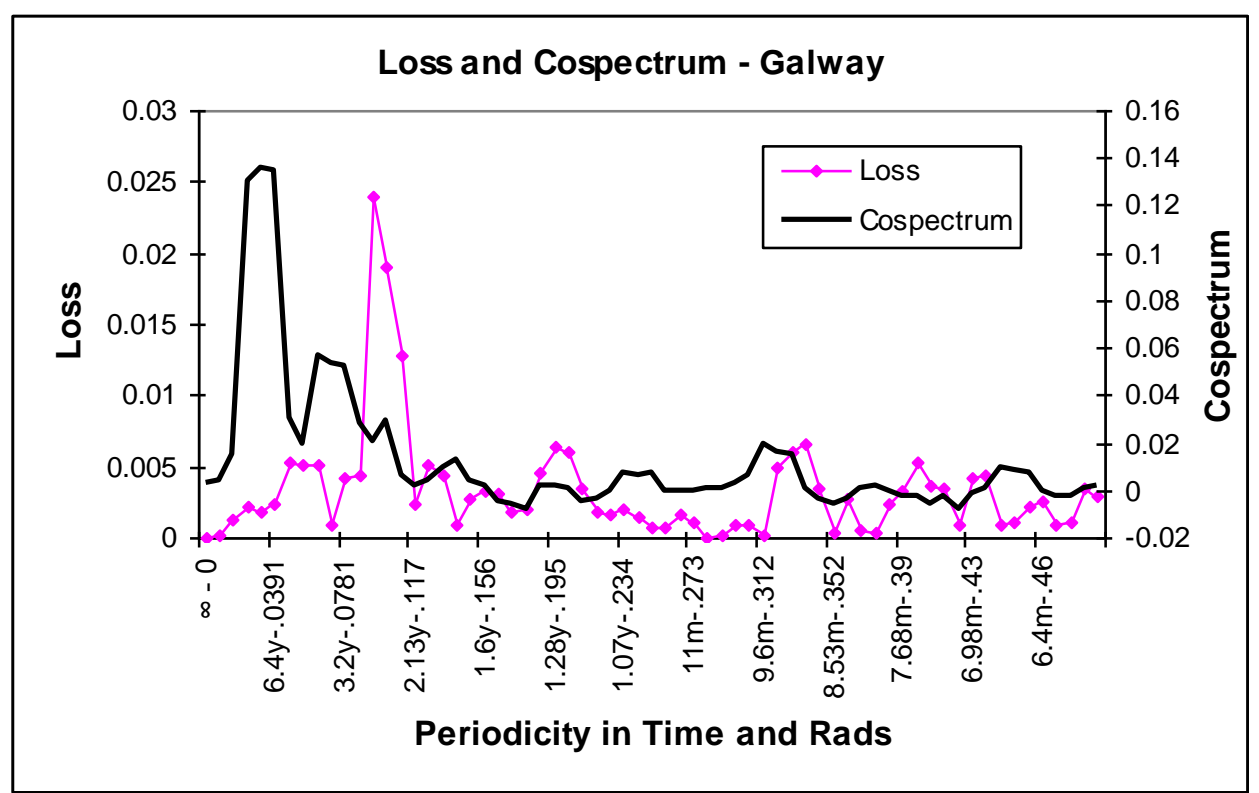

Figure a10: Cospectrum and Loss Spectra, Galway 


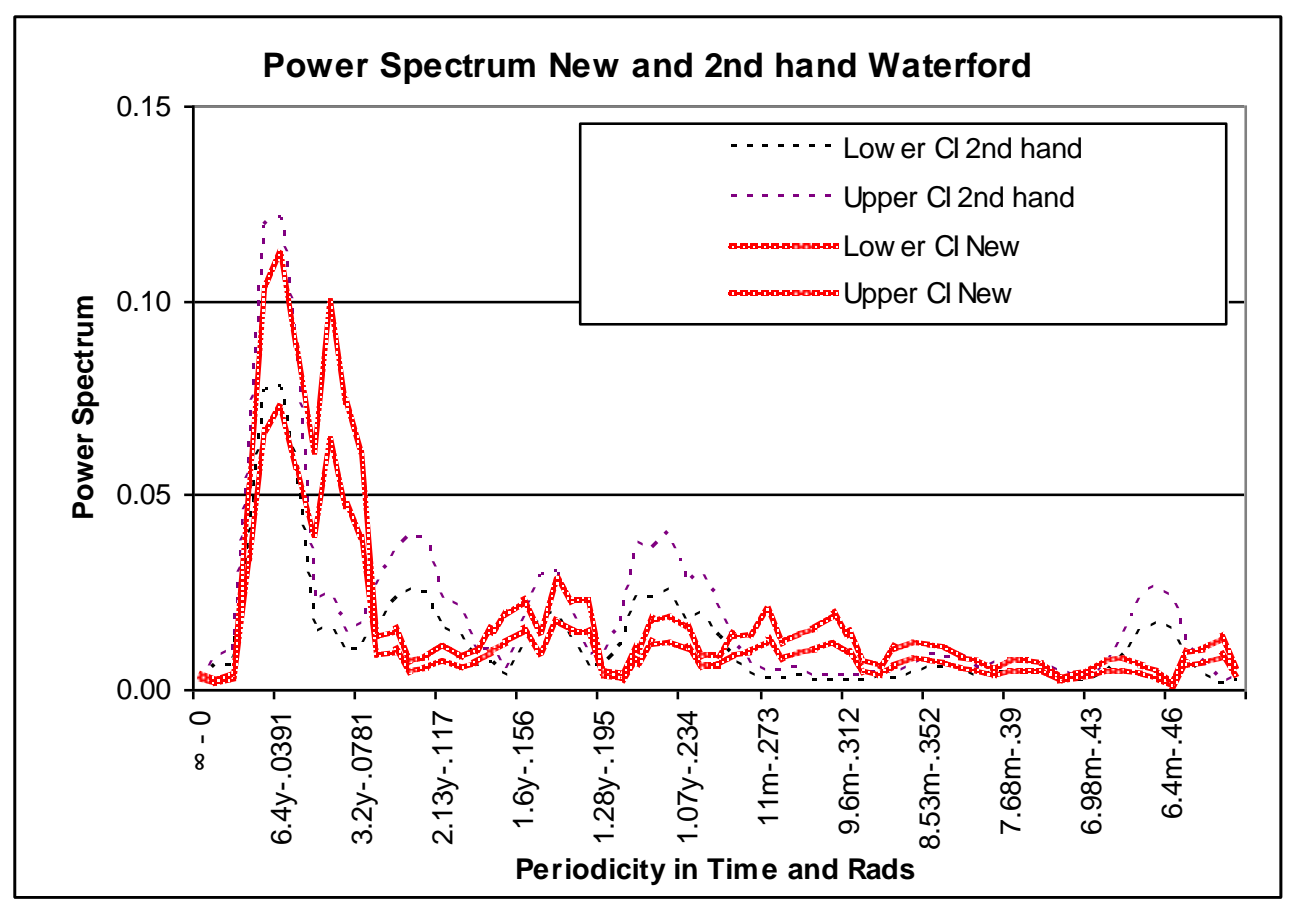

Figure a11: Confidence Intervals of the Power Spectra of New and $2^{\text {nd }}$ hand, Waterford 


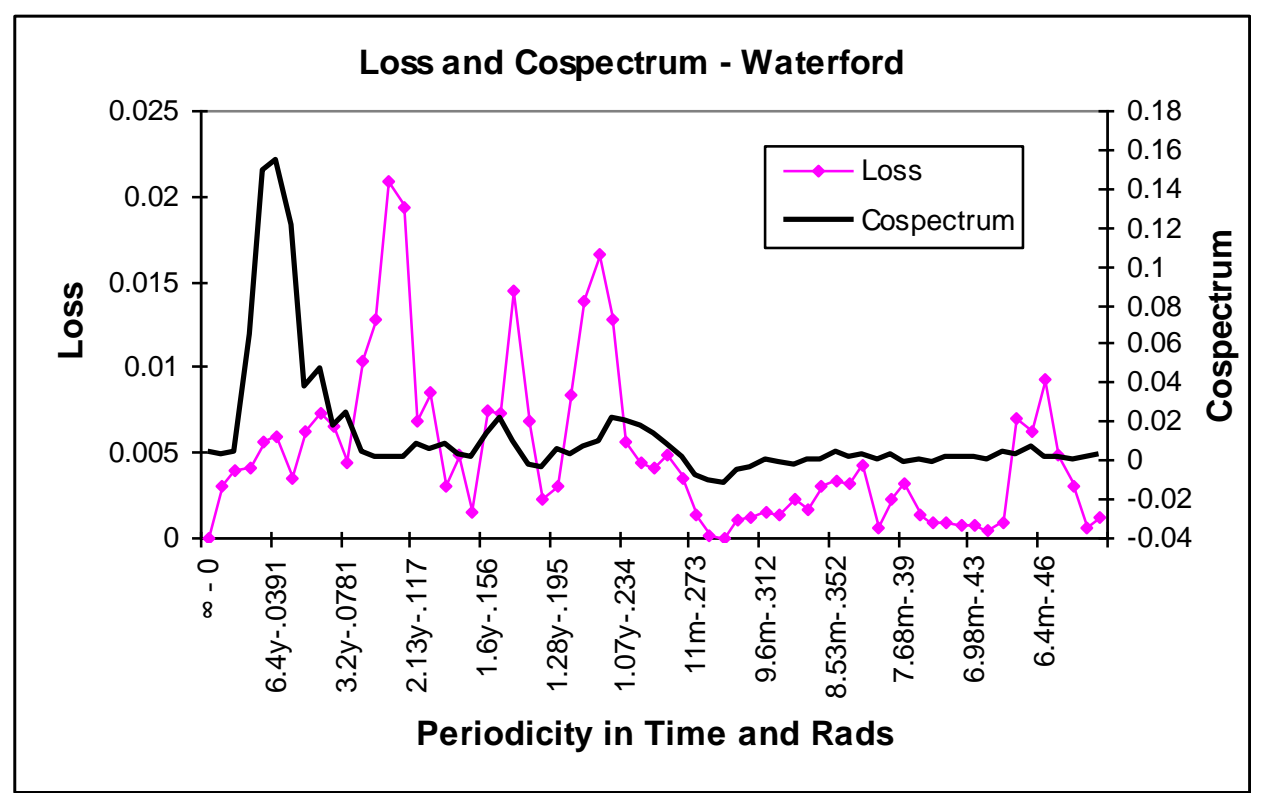

Figure a12: Cospectrum and Loss Spectra, Waterford

\begin{tabular}{|l|c|l|l|l|}
\hline House Price & Max $€$ & Quarter & Crossover & Crossover2 \\
\hline Eire New & 292,728 & Q1 2007 & & \\
\hline Eire 2 & 345,396 & Q4 2006 & Q1 1997 & \\
\hline Dublin New & 370,703 & Q3 2006 & & \\
\hline Dublin 2 & 456,338 & Q3 2006 & Q4 1993 & \\
\hline Cork New & 294,927 & Q3 2007 & & Q4 2009 \\
\hline Cork 2 & 327,891 & Q1 2007 & Q1 2000 & \\
\hline Galway New & 277,856 & Q4 2006 & Q4 1979 & \\
\hline Galway 2 & 321,703 & Q4 2006 & Q3 1998 & \\
\hline Limerick New & 267,586 & Q1 2008 & & Q3 2005 \\
\hline Limerick 2 & 248,925 & Q1 2007 & Q2 2001 & \\
\hline Waterford New & 267,308 & Q3 2007 & & Q2 2007 \\
\hline Waterford 2 & 266,138 & Q1 2007 & Q2 2002 & \\
\hline Rural New & 269,861 & Q2 2007 & & \\
\hline Rural2 & 281,574 & Q1 2007 & Q2 2000 & \\
\hline & Max Q & & & \\
\hline $\begin{array}{l}\text { Private } \\
\text { Construction }\end{array}$ & 18393 & Q2 2005 & & \\
\hline All Construction & 19811 & Q2 2005 & & \\
\hline
\end{tabular}

Table 1 House Price Descriptors: Trend 


\begin{tabular}{|c|c|c|c|c|c|c|c|c|}
\hline \multirow{2}{*}{$\mathrm{ADF}$} & \multicolumn{2}{|c|}{ Eire } & \multicolumn{2}{|c|}{ Dublin } & \multicolumn{2}{|c|}{ Cork } & \multirow{2}{*}{$\begin{array}{l}\text { Rural } \\
\text { New }\end{array}$} & \multirow{2}{*}{$\begin{array}{l}\text { Critical } \\
\text { value }\end{array}$} \\
\hline & New & $2 \mathrm{ndH}$ & New & $2 \mathrm{ndH}$ & New & $2 \mathrm{ndH}$ & & \\
\hline 4lags trend & -2.376 & -1.973 & -2.377 & -1.852 & -2.093 & -1.376 & -1.899 & -3.44 \\
\hline \multirow[t]{3}{*}{ 4lags } & -1.204 & -1.385 & -1.244 & -1.374 & -0.980 & -1.164 & -1.241 & -2.88 \\
\hline & \multicolumn{2}{|c|}{ Galway } & \multicolumn{2}{|c|}{ Limerick } & \multicolumn{2}{|c|}{ Waterford } & Rural & \\
\hline & New & $2 \mathrm{ndH}$ & New & $2 \mathrm{ndH}$ & New & $2 \mathrm{ndH}$ & $2 \mathrm{ndH}$ & \\
\hline 4lags trend & -0.838 & -1.184 & -1.407 & -1.646 & -1.555 & -0.743 & -1.493 & -3.44 \\
\hline 4lags & -1.508 & -0.984 & -1.338 & -1.320 & -1.265 & -1.447 & -1.649 & -2.88 \\
\hline
\end{tabular}

ADF Test results for New and Second-hand

Table a1 Augmented Dickey Fuller Tests 


\begin{tabular}{|c|c|c|c|c|c|c|}
\hline Periodicity & \multicolumn{2}{|c|}{ Power Spectrum } & \multicolumn{2}{|c|}{ 2nd hand } & \multicolumn{2}{|c|}{ New } \\
\hline $\begin{array}{r}\text { Time Years/ Months } \\
\text { Rads }\end{array}$ & 2nd hand & New & $\begin{array}{l}\text { Lower } \\
\text { CIL }\end{array}$ & $\begin{array}{l}\text { Upper } \\
\text { CIL }\end{array}$ & $\begin{array}{l}\text { Lower } \\
\text { CIL }\end{array}$ & $\begin{array}{l}\text { Upper } \\
\text { CIL }\end{array}$ \\
\hline$\infty-0$ & 0.0023 & 0.0014 & 0.0018 & 0.0029 & 0.0012 & 0.0018 \\
\hline 32.00 & 0.0023 & 0.0012 & 0.0019 & 0.0030 & 0.001 & 0.0015 \\
\hline 16.00 & 0.0041 & 0.0039 & 0.0033 & 0.0052 & 0.0032 & 0.005 \\
\hline 10.67 & 0.0716 & 0.0609 & 0.0582 & 0.0905 & 0.0495 & 0.077 \\
\hline 8.00 & 0.0828 & 0.0723 & 0.0673 & 0.1048 & 0.0588 & 0.0916 \\
\hline 6.4years-.0391 & 0.0858 & 0.0756 & 0.0697 & 0.1085 & 0.0615 & 0.0957 \\
\hline 5.33 & 0.0243 & 0.0235 & 0.0197 & 0.0307 & 0.0191 & 0.0297 \\
\hline 4.57 & 0.0162 & 0.0134 & 0.0132 & 0.0206 & 0.0109 & 0.0169 \\
\hline 4.00 & 0.0145 & 0.0119 & 0.0118 & 0.0183 & 0.0097 & 0.0151 \\
\hline 3.56 & 0.0081 & 0.0076 & 0.0065 & 0.0102 & 0.0062 & 0.0096 \\
\hline 3.2 years-.0781 & 0.0044 & 0.0061 & 0.0035 & 0.0055 & 0.005 & 0.0077 \\
\hline 2.91 & 0.0036 & 0.0031 & 0.0029 & 0.0046 & 0.0025 & 0.0039 \\
\hline 2.67 & 0.0100 & 0.0027 & 0.0081 & 0.0126 & 0.0022 & 0.0034 \\
\hline 2.46 & 0.0104 & 0.0032 & 0.0085 & 0.0132 & 0.0026 & 0.0041 \\
\hline 2.29 & 0.0112 & 0.0017 & 0.0091 & 0.0142 & 0.0014 & 0.0022 \\
\hline 2.13years-.117 & 0.0052 & 0.0020 & 0.0043 & 0.0066 & 0.0016 & 0.0025 \\
\hline 2.00 & 0.0044 & 0.0021 & 0.0036 & 0.0056 & 0.0017 & 0.0027 \\
\hline 1.88 & 0.0018 & 0.0021 & 0.0015 & 0.0023 & 0.0017 & 0.0026 \\
\hline 1.78 & 0.0010 & 0.0012 & 0.0008 & 0.0013 & 0.001 & 0.0015 \\
\hline 1.68 & 0.0007 & 0.0002 & 0.0006 & 0.0009 & 0.0002 & 0.0002 \\
\hline 1.6years-.156 & 0.0008 & 0.0009 & 0.0007 & 0.001 & 0.0007 & 0.0012 \\
\hline 1.52 & 0.0010 & 0.0012 & 0.0008 & 0.0013 & 0.001 & 0.0016 \\
\hline 1.45 & 0.0017 & 0.0015 & 0.0014 & 0.0022 & 0.0012 & 0.0018 \\
\hline 1.39 & 0.0028 & 0.0010 & 0.0023 & 0.0036 & 0.0008 & 0.0013 \\
\hline 1.33 & 0.0028 & 0.0008 & 0.0023 & 0.0035 & 0.0006 & 0.001 \\
\hline 1.28years-.195 & 0.0022 & 0.0013 & 0.0018 & 0.0028 & 0.0011 & 0.0017 \\
\hline 1.23 & 0.0009 & 0.0011 & 0.0007 & 0.0011 & 0.0009 & 0.0014 \\
\hline 1.19 & 0.0018 & 0.0012 & 0.0015 & 0.0023 & 0.001 & 0.0016 \\
\hline 1.14 & 0.0017 & 0.0006 & 0.0014 & 0.0022 & 0.0005 & 0.0007 \\
\hline 1.10 & 0.0023 & 0.0007 & 0.0019 & 0.0029 & 0.0006 & 0.0009 \\
\hline 1.07years-.234 & 0.0021 & 0.0021 & 0.0017 & 0.0026 & 0.0017 & 0.0026 \\
\hline 1.03 & 0.0058 & 0.0021 & 0.0047 & 0.0074 & 0.0017 & 0.0026 \\
\hline 1.00 & 0.0056 & 0.0022 & 0.0045 & 0.0071 & 0.0018 & 0.0027 \\
\hline 11.64 & 0.0043 & 0.0008 & 0.0035 & 0.0055 & 0.0006 & 0.001 \\
\hline 11.29 & 0.0009 & 0.0007 & 0.0007 & 0.0012 & 0.0006 & 0.0009 \\
\hline 11months-.273 & 0.0004 & 0.0005 & 0.0004 & 0.0006 & 0.0004 & 0.0007 \\
\hline 10.67 & 0.0005 & 0.0005 & 0.0004 & 0.0006 & 0.0004 & 0.0006 \\
\hline 10.38 & 0.0006 & 0.0004 & 0.0005 & 0.0008 & 0.0004 & 0.0005 \\
\hline 10.11 & 0.0007 & 0.0010 & 0.0006 & 0.0009 & 0.0009 & 0.0013 \\
\hline 9.85 & 0.0007 & 0.0012 & 0.0006 & 0.0009 & 0.0009 & 0.0015 \\
\hline 9.6months-.312 & 0.0011 & 0.0016 & 0.0009 & 0.0014 & 0.0013 & 0.002 \\
\hline 9.37 & 0.0014 & 0.0011 & 0.0011 & 0.0018 & 0.0009 & 0.0014 \\
\hline 9.14 & 0.0014 & 0.0009 & 0.0011 & 0.0018 & 0.0008 & 0.0012 \\
\hline 8.93 & 0.0007 & 0.0005 & 0.0006 & 0.0009 & 0.0004 & 0.0006 \\
\hline 8.73 & 0.0008 & 0.0002 & 0.0006 & 0.001 & 0.0002 & 0.0003 \\
\hline 8.53months-..352 & 0.0010 & 0.0003 & 0.0008 & 0.0013 & 0.0002 & 0.0004 \\
\hline 8.35 & 0.0011 & 0.0003 & 0.0009 & 0.0014 & 0.0002 & 0.0004 \\
\hline 8.17 & 0.0007 & 0.0002 & 0.0006 & 0.0009 & 0.0001 & 0.0002 \\
\hline 8.00 & 0.0005 & 0.0000 & 0.0004 & 0.0007 & $3 \mathrm{E}-05$ & $5 \mathrm{E}-05$ \\
\hline 7.84 & 0.0004 & 0.0000 & 0.0003 & 0.0005 & $3 \mathrm{E}-05$ & $5 \mathrm{E}-05$ \\
\hline 7.68months-..39 & 0.0003 & 0.0002 & 0.0003 & 0.0004 & 0.0001 & 0.0002 \\
\hline 7.53 & 0.0005 & 0.0002 & 0.0004 & 0.0006 & 0.0002 & 0.0003 \\
\hline 7.38 & 0.0004 & 0.0002 & 0.0003 & 0.0005 & 0.0002 & 0.0003 \\
\hline 7.25 & 0.0007 & 0.0003 & 0.0006 & 0.0009 & 0.0003 & 0.0004 \\
\hline 7.11 & 0.0009 & 0.0003 & 0.0007 & 0.0011 & 0.0002 & 0.0003 \\
\hline 6.98months-.43 & 0.0009 & 0.0003 & 0.0007 & 0.0011 & 0.0002 & 0.0004 \\
\hline 6.86 & 0.0005 & 0.0001 & 0.0004 & 0.0006 & 0.0001 & 0.0002 \\
\hline
\end{tabular}




\begin{tabular}{|rr|rr|rrrr|} 
& $\mathbf{6 . 7 4}$ & $\mathbf{0 . 0 0 0 2}$ & 0.0002 & 0.0001 & 0.0002 & 0.0001 & 0.0002 \\
& $\mathbf{6 . 6 2}$ & $\mathbf{0 . 0 0 0 8}$ & 0.0001 & 0.0006 & 0.001 & 0.0001 & 0.0002 \\
& $\mathbf{6 . 5 1}$ & $\mathbf{0 . 0 0 0 9}$ & 0.0001 & 0.0007 & 0.0011 & $9 \mathrm{E}-05$ & 0.0001 \\
$\mathbf{6 . 4 m o n t h s - . 4 6}$ & & $\mathbf{0 . 0 0 0 8}$ & 0.0001 & 0.0007 & 0.001 & $1 \mathrm{E}-04$ & 0.0001 \\
& $\mathbf{6 . 3 0}$ & $\mathbf{0 . 0 0 0 2}$ & 0.0001 & 0.0002 & 0.0003 & $9 \mathrm{E}-05$ & 0.0001 \\
& $\mathbf{6 . 1 9}$ & 0.0007 & 0.0006 & 0.0006 & 0.0009 & 0.0005 & 0.0007 \\
& $\mathbf{6 . 1 0}$ & $\mathbf{0 . 0 0 3 7}$ & 0.0007 & 0.003 & 0.0047 & 0.0006 & 0.0009 \\
& $\mathbf{6 . 0 0}$ & $\mathbf{0 . 0 0 4 2}$ & 0.0012 & 0.0034 & 0.0053 & 0.0009 & 0.0015 \\
\hline
\end{tabular}

Those in bold are significantly above than the other spectrum value.

Table a2 Power Spectra with 95\% confidence interval limits, Eire 


\begin{tabular}{|c|c|c|c|c|c|c|}
\hline Periodicity & \multicolumn{2}{|c|}{ Power Spectrum } & \multicolumn{2}{|c|}{ 2nd hand } & \multicolumn{2}{|c|}{ New } \\
\hline $\begin{array}{r}\text { Time Years/ Months } \\
\text { Rads }\end{array}$ & 2nd hand & New & $\begin{array}{l}\text { Lower } \\
\text { CIL }\end{array}$ & $\begin{array}{l}\text { Upper } \\
\text { CIL }\end{array}$ & $\begin{array}{l}\text { Lower } \\
\text { CIL }\end{array}$ & $\begin{array}{l}\text { Upper } \\
\text { CIL }\end{array}$ \\
\hline$\infty-0$ & 0.0030 & 0.0023 & 0.0024 & 0.0038 & 0.0019 & 0.0029 \\
\hline 32.00 & 0.0024 & 0.0026 & 0.0019 & 0.0030 & 0.0021 & 0.0033 \\
\hline 16.00 & 0.0063 & 0.0107 & 0.0051 & 0.008 & 0.0087 & 0.0136 \\
\hline 10.67 & 0.1181 & 0.1411 & 0.096 & 0.1494 & 0.1147 & 0.1785 \\
\hline 8.00 & 0.1270 & 0.1522 & 0.1032 & 0.1606 & 0.1238 & 0.1926 \\
\hline 6.4years-.0391 & 0.1346 & 0.1551 & 0.1094 & 0.1703 & 0.1261 & 0.1963 \\
\hline 5.33 & 0.0330 & 0.0384 & 0.0269 & 0.0418 & 0.0312 & 0.0486 \\
\hline 4.57 & 0.0292 & 0.0339 & 0.0237 & 0.0369 & 0.0276 & 0.0429 \\
\hline 4.00 & 0.0217 & 0.0312 & 0.0176 & 0.0275 & 0.0254 & 0.0395 \\
\hline 3.56 & 0.0104 & 0.0238 & 0.0084 & 0.0131 & 0.0194 & 0.0301 \\
\hline 3.2 years-.0781 & 0.0046 & 0.0164 & 0.0037 & 0.0058 & 0.0133 & 0.0207 \\
\hline 2.91 & 0.0085 & 0.0134 & 0.0069 & 0.0108 & 0.0109 & 0.0169 \\
\hline 2.67 & 0.0145 & 0.0080 & 0.0118 & 0.0184 & 0.0065 & 0.0101 \\
\hline 2.46 & 0.0162 & 0.0085 & 0.0132 & 0.0205 & 0.0069 & 0.0108 \\
\hline 2.29 & 0.0117 & 0.0033 & 0.0095 & 0.0148 & 0.0027 & 0.0042 \\
\hline 2.13years-.117 & 0.0069 & 0.0050 & 0.0056 & 0.0087 & 0.004 & 0.0063 \\
\hline 2.00 & 0.0059 & 0.0046 & 0.0048 & 0.0074 & 0.0037 & 0.0058 \\
\hline 1.88 & 0.0029 & 0.0072 & 0.0024 & 0.0037 & 0.0058 & 0.0091 \\
\hline 1.78 & 0.0019 & 0.0036 & 0.0015 & 0.0023 & 0.0029 & 0.0046 \\
\hline 1.68 & 0.0015 & 0.0029 & 0.0013 & 0.002 & 0.0023 & 0.0037 \\
\hline 1.6years-.156 & 0.0011 & 0.0009 & 0.0009 & 0.0013 & 0.0007 & 0.0011 \\
\hline 1.52 & 0.0013 & 0.0013 & 0.0011 & 0.0017 & 0.0011 & 0.0017 \\
\hline 1.45 & 0.0014 & 0.0013 & 0.0011 & 0.0018 & 0.0011 & 0.0017 \\
\hline 1.39 & 0.0038 & 0.0010 & 0.0031 & 0.0048 & 0.0008 & 0.0013 \\
\hline 1.33 & 0.0035 & 0.0008 & 0.0028 & 0.0044 & 0.0007 & 0.001 \\
\hline 1.28years-.195 & 0.0033 & 0.0023 & 0.0027 & 0.0042 & 0.0019 & 0.0029 \\
\hline 1.23 & 0.0016 & 0.0027 & 0.0013 & 0.0021 & 0.0022 & 0.0035 \\
\hline 1.19 & 0.0034 & 0.0024 & 0.0028 & 0.0043 & 0.0019 & 0.003 \\
\hline 1.14 & 0.0031 & 0.0012 & 0.0025 & 0.0039 & 0.0009 & 0.0015 \\
\hline 1.10 & 0.0037 & 0.0004 & 0.003 & 0.0047 & 0.0003 & 0.0005 \\
\hline 1.07years-.234 & 0.0028 & 0.0009 & 0.0023 & 0.0036 & 0.0007 & 0.0012 \\
\hline 1.03 & 0.0109 & 0.0029 & 0.0089 & 0.0138 & 0.0024 & 0.0037 \\
\hline 1.00 & 0.0101 & 0.0030 & 0.0082 & 0.0127 & 0.0024 & 0.0038 \\
\hline 11.64 & 0.0088 & 0.0027 & 0.0071 & 0.0111 & 0.0022 & 0.0034 \\
\hline 11.29 & 0.0015 & 0.0006 & 0.0012 & 0.0019 & 0.0005 & 0.0007 \\
\hline 11months-.273 & 0.0012 & 0.0009 & 0.001 & 0.0016 & 0.0007 & 0.0011 \\
\hline 10.67 & 0.0014 & 0.0006 & 0.0012 & 0.0018 & 0.0005 & 0.0008 \\
\hline 10.38 & 0.0007 & 0.0006 & 0.0006 & 0.0009 & 0.0005 & 0.0008 \\
\hline 10.11 & 0.0006 & 0.0004 & 0.0005 & 0.0008 & 0.0003 & 0.0005 \\
\hline 9.85 & 0.0004 & 0.0004 & 0.0003 & 0.0004 & 0.0003 & 0.0005 \\
\hline 9.6months-.312 & 0.0011 & 0.0009 & 0.0009 & 0.0013 & 0.0007 & 0.0012 \\
\hline 9.37 & 0.0017 & 0.0017 & 0.0014 & 0.0021 & 0.0014 & 0.0022 \\
\hline 9.14 & 0.0020 & 0.0024 & 0.0016 & 0.0025 & 0.002 & 0.0031 \\
\hline 8.93 & 0.0011 & 0.0018 & 0.0009 & 0.0014 & 0.0015 & 0.0023 \\
\hline 8.73 & 0.0008 & 0.0013 & 0.0006 & 0.001 & 0.0011 & 0.0017 \\
\hline 8.53months-..352 & 0.0006 & 0.0010 & 0.0005 & 0.0008 & 0.0008 & 0.0013 \\
\hline 8.35 & 0.0009 & 0.0010 & 0.0007 & 0.0012 & 0.0008 & 0.0013 \\
\hline 8.17 & 0.0006 & 0.0005 & 0.0005 & 0.0008 & 0.0004 & 0.0006 \\
\hline 8.00 & 0.0006 & 0.0004 & 0.0005 & 0.0007 & 0.0003 & 0.0005 \\
\hline 7.84 & 0.0006 & 0.0005 & 0.0005 & 0.0007 & 0.0004 & 0.0007 \\
\hline 7.68months-..39 & 0.0005 & 0.0007 & 0.0004 & 0.0006 & 0.0005 & 0.0008 \\
\hline 7.53 & 0.0009 & 0.0014 & 0.0008 & 0.0012 & 0.0011 & 0.0017 \\
\hline 7.38 & 0.0010 & 0.0012 & 0.0008 & 0.0013 & 0.001 & 0.0015 \\
\hline 7.25 & 0.0020 & 0.0016 & 0.0016 & 0.0025 & 0.0013 & 0.002 \\
\hline 7.11 & 0.0019 & 0.0009 & 0.0015 & 0.0024 & 0.0007 & 0.0011 \\
\hline 6.98months-.43 & 0.0017 & 0.0012 & 0.0014 & 0.0022 & 0.0009 & 0.0015 \\
\hline 6.86 & 0.0012 & 0.0006 & 0.001 & 0.0015 & 0.0005 & 0.0008 \\
\hline
\end{tabular}




\begin{tabular}{|rr|rr|rrrr|} 
& $\mathbf{6 . 7 4}$ & 0.0007 & 0.0007 & 0.0006 & 0.0009 & 0.0006 & 0.0009 \\
& $\mathbf{6 . 6 2}$ & $\mathbf{0 . 0 0 1 5}$ & 0.0005 & 0.0012 & 0.0019 & 0.0004 & 0.0007 \\
& $\mathbf{6 . 5 1}$ & $\mathbf{0 . 0 0 1 4}$ & 0.0007 & 0.0011 & 0.0018 & 0.0006 & 0.0009 \\
$\mathbf{6 . 4 m o n t h s - . 4 6}$ & & $\mathbf{0 . 0 0 1 4}$ & 0.0007 & 0.0011 & 0.0018 & 0.0006 & 0.0009 \\
& $\mathbf{6 . 3 0}$ & 0.0006 & $\mathbf{0 . 0 0 1 3}$ & 0.0005 & 0.0008 & 0.0011 & 0.0017 \\
& $\mathbf{6 . 1 9}$ & 0.0010 & $\mathbf{0 . 0 0 1 7}$ & 0.0009 & 0.0013 & 0.0013 & 0.0021 \\
& $\mathbf{6 . 1 0}$ & $\mathbf{0 . 0 0 6 7}$ & 0.0012 & 0.0054 & 0.0084 & 0.001 & 0.0016 \\
& $\mathbf{6 . 0 0}$ & $\mathbf{0 . 0 0 7 4}$ & 0.0010 & 0.006 & 0.0093 & 0.0008 & 0.0013 \\
\hline
\end{tabular}

Those in bold are significantly above than the other spectrum value.

Table a3 Power Spectra with 95\% confidence interval limits: Dublin 


\begin{tabular}{|c|c|c|c|c|c|c|}
\hline Periodicity & \multicolumn{2}{|c|}{ Power Spectrum } & \multicolumn{2}{|c|}{ 2nd hand } & \multicolumn{2}{|c|}{ New } \\
\hline $\begin{array}{r}\text { Time Years/ Months } \\
\text { Rads }\end{array}$ & 2nd hand & New & $\begin{array}{l}\text { Lower } \\
\text { CIL }\end{array}$ & $\begin{array}{l}\text { Upper } \\
\text { CIL }\end{array}$ & $\begin{array}{l}\text { Lower } \\
\text { CIL }\end{array}$ & $\begin{array}{l}\text { Upper } \\
\text { CIL }\end{array}$ \\
\hline$\infty-0$ & 0.0017 & 0.0014 & 0.0014 & 0.0021 & 0.0011 & 0.0017 \\
\hline 32.00 & 0.0027 & 0.0008 & 0.0022 & 0.0034 & 0.0007 & 0.001 \\
\hline 16.00 & 0.0028 & 0.0026 & 0.0023 & 0.0036 & 0.0021 & 0.0033 \\
\hline 10.67 & 0.0471 & 0.0474 & 0.0383 & 0.0595 & 0.0385 & 0.06 \\
\hline 8.00 & 0.0590 & 0.0620 & 0.048 & 0.0747 & 0.0504 & 0.0784 \\
\hline 6.4years-.0391 & 0.0605 & 0.0636 & 0.0492 & 0.0766 & 0.0517 & 0.0805 \\
\hline 5.33 & 0.0231 & 0.0205 & 0.0188 & 0.0292 & 0.0167 & 0.0259 \\
\hline 4.57 & 0.0206 & 0.0065 & 0.0168 & 0.0261 & 0.0053 & 0.0083 \\
\hline 4.00 & 0.0208 & 0.0091 & 0.0169 & 0.0263 & 0.0074 & 0.0115 \\
\hline 3.56 & 0.0148 & 0.0074 & 0.012 & 0.0187 & 0.006 & 0.0094 \\
\hline 3.2 years-.0781 & 0.0059 & 0.0076 & 0.0048 & 0.0074 & 0.0061 & 0.0096 \\
\hline 2.91 & 0.0055 & 0.0020 & 0.0045 & 0.0069 & 0.0017 & 0.0026 \\
\hline 2.67 & 0.0157 & 0.0017 & 0.0128 & 0.0199 & 0.0014 & 0.0022 \\
\hline 2.46 & 0.0153 & 0.0028 & 0.0125 & 0.0194 & 0.0023 & 0.0035 \\
\hline 2.29 & 0.0177 & 0.0025 & 0.0144 & 0.0224 & 0.0021 & 0.0032 \\
\hline 2.13years-.117 & 0.0075 & 0.0035 & 0.0061 & 0.0095 & 0.0029 & 0.0045 \\
\hline 2.00 & 0.0057 & 0.0028 & 0.0047 & 0.0073 & 0.0023 & 0.0036 \\
\hline 1.88 & 0.0031 & 0.0029 & 0.0025 & 0.0039 & 0.0024 & 0.0037 \\
\hline 1.78 & 0.0027 & 0.0019 & 0.0022 & 0.0034 & 0.0015 & 0.0024 \\
\hline 1.68 & 0.0035 & 0.0011 & 0.0029 & 0.0045 & 0.0009 & 0.0013 \\
\hline 1.6years-.156 & 0.0048 & 0.0011 & 0.0039 & 0.0061 & 0.0009 & 0.0014 \\
\hline 1.52 & 0.0044 & 0.0017 & 0.0036 & 0.0056 & 0.0014 & 0.0022 \\
\hline 1.45 & 0.0047 & 0.0015 & 0.0038 & 0.006 & 0.0013 & 0.002 \\
\hline 1.39 & 0.0038 & 0.0030 & 0.0031 & 0.0048 & 0.0024 & 0.0038 \\
\hline 1.33 & 0.0033 & 0.0024 & 0.0027 & 0.0042 & 0.002 & 0.0031 \\
\hline 1.28years-.195 & 0.0020 & 0.0022 & 0.0016 & 0.0025 & 0.0018 & 0.0028 \\
\hline 1.23 & 0.0005 & 0.0012 & 0.0004 & 0.0007 & 0.001 & 0.0016 \\
\hline 1.19 & 0.0012 & 0.0009 & 0.001 & 0.0015 & 0.0007 & 0.0011 \\
\hline 1.14 & 0.0014 & 0.0011 & 0.0011 & 0.0018 & 0.0009 & 0.0014 \\
\hline 1.10 & 0.0016 & 0.0006 & 0.0013 & 0.002 & 0.0005 & 0.0007 \\
\hline 1.07years-.234 & 0.0017 & 0.0026 & 0.0013 & 0.0021 & 0.0021 & 0.0033 \\
\hline 1.03 & 0.0032 & 0.0023 & 0.0026 & 0.0041 & 0.0019 & 0.003 \\
\hline 1.00 & 0.0040 & 0.0032 & 0.0033 & 0.0051 & 0.0026 & 0.004 \\
\hline 11.64 & 0.0029 & 0.0012 & 0.0024 & 0.0037 & 0.0009 & 0.0015 \\
\hline 11.29 & 0.0020 & 0.0012 & 0.0016 & 0.0025 & 0.0009 & 0.0015 \\
\hline 11months-.273 & 0.0013 & 0.0008 & 0.0011 & 0.0016 & 0.0007 & 0.001 \\
\hline 10.67 & 0.0014 & 0.0017 & 0.0011 & 0.0017 & 0.0014 & 0.0022 \\
\hline 10.38 & 0.0015 & 0.0019 & 0.0013 & 0.002 & 0.0015 & 0.0024 \\
\hline 10.11 & 0.0020 & 0.0033 & 0.0016 & 0.0026 & 0.0027 & 0.0041 \\
\hline 9.85 & 0.0021 & 0.0023 & 0.0017 & 0.0026 & 0.0018 & 0.0029 \\
\hline 9.6months-.312 & 0.0015 & 0.0023 & 0.0013 & 0.002 & 0.0019 & 0.0029 \\
\hline 9.37 & 0.0013 & 0.0011 & 0.0011 & 0.0017 & 0.0009 & 0.0014 \\
\hline 9.14 & 0.0014 & 0.0012 & 0.0011 & 0.0017 & 0.001 & 0.0016 \\
\hline 8.93 & 0.0015 & 0.0011 & 0.0012 & 0.0019 & 0.0009 & 0.0014 \\
\hline 8.73 & 0.0011 & 0.0003 & 0.0009 & 0.0014 & 0.0002 & 0.0004 \\
\hline 8.53months-..352 & 0.0010 & 0.0002 & 0.0008 & 0.0013 & 0.0001 & 0.0002 \\
\hline 8.35 & 0.0007 & 0.0002 & 0.0006 & 0.0009 & 0.0001 & 0.0002 \\
\hline 8.17 & 0.0007 & 0.0004 & 0.0005 & 0.0009 & 0.0004 & 0.0006 \\
\hline 8.00 & 0.0014 & 0.0006 & 0.0011 & 0.0017 & 0.0005 & 0.0008 \\
\hline 7.84 & 0.0017 & 0.0006 & 0.0014 & 0.0022 & 0.0005 & 0.0008 \\
\hline 7.68months-..39 & 0.0016 & 0.0004 & 0.0013 & 0.0021 & 0.0003 & 0.0004 \\
\hline 7.53 & 0.0009 & 0.0002 & 0.0007 & 0.0012 & 0.0001 & 0.0002 \\
\hline 7.38 & 0.0004 & 0.0001 & 0.0003 & 0.0005 & $1 \mathrm{E}-04$ & 0.0002 \\
\hline 7.25 & 0.0007 & 0.0003 & 0.0005 & 0.0008 & 0.0002 & 0.0004 \\
\hline 7.11 & 0.0009 & 0.0002 & 0.0008 & 0.0012 & 0.0002 & 0.0003 \\
\hline 6.98months-.43 & 0.0008 & 0.0004 & 0.0007 & 0.0011 & 0.0003 & 0.0005 \\
\hline 6.86 & 0.0013 & 0.0002 & 0.0011 & 0.0017 & 0.0002 & 0.0003 \\
\hline
\end{tabular}




\begin{tabular}{|rr|rr|rrrr|} 
& $\mathbf{6 . 7 4}$ & $\mathbf{0 . 0 0 1 2}$ & 0.0002 & 0.001 & 0.0016 & 0.0002 & 0.0003 \\
& $\mathbf{6 . 6 2}$ & $\mathbf{0 . 0 0 2 2}$ & 0.0002 & 0.0018 & 0.0028 & 0.0001 & 0.0002 \\
& $\mathbf{6 . 5 1}$ & $\mathbf{0 . 0 0 1 5}$ & 0.0002 & 0.0012 & 0.0019 & 0.0002 & 0.0003 \\
$\mathbf{6 . 4 m o n t h s - . 4 6}$ & & $\mathbf{0 . 0 0 1 3}$ & 0.0004 & 0.001 & 0.0016 & 0.0003 & 0.0005 \\
& $\mathbf{6 . 3 0}$ & $\mathbf{0 . 0 0 0 7}$ & 0.0003 & 0.0005 & 0.0008 & 0.0003 & 0.0004 \\
& $\mathbf{6 . 1 9}$ & $\mathbf{0 . 0 0 1 4}$ & 0.0009 & 0.0012 & 0.0018 & 0.0007 & 0.0011 \\
& $\mathbf{6 . 1 0}$ & $\mathbf{0 . 0 0 2 3}$ & 0.0008 & 0.0019 & 0.003 & 0.0006 & 0.001 \\
& $\mathbf{6 . 0 0}$ & $\mathbf{0 . 0 0 3 0}$ & 0.0014 & 0.0024 & 0.0038 & 0.0011 & 0.0017 \\
\hline
\end{tabular}

Those in bold are significantly above than the other spectrum value.

Table a4 Power Spectra with 95\% confidence interval limits, Rural 


\begin{tabular}{|c|c|c|c|c|c|c|}
\hline Periodicity & \multicolumn{2}{|c|}{ Power Spectrum } & \multicolumn{2}{|c|}{ 2nd hand } & \multicolumn{2}{|c|}{ New } \\
\hline $\begin{array}{r}\text { Time Years/ Months } \\
\text { Rads }\end{array}$ & 2nd hand & New & $\begin{array}{l}\text { Lower } \\
\text { CIL }\end{array}$ & $\begin{array}{l}\text { Upper } \\
\text { CIL }\end{array}$ & $\begin{array}{l}\text { Lower } \\
\text { CIL }\end{array}$ & $\begin{array}{l}\text { Upper } \\
\text { CIL }\end{array}$ \\
\hline$\infty-0$ & 0.0026 & 0.0014 & 0.0021 & 0.0033 & 0.0012 & 0.0018 \\
\hline 32.00 & 0.0038 & 0.0014 & 0.0031 & 0.0048 & 0.0012 & 0.0018 \\
\hline 16.00 & 0.0046 & 0.0045 & 0.0038 & 0.0059 & 0.0037 & 0.0057 \\
\hline 10.67 & 0.0415 & 0.0389 & 0.0337 & 0.0525 & 0.0317 & 0.0493 \\
\hline 8.00 & 0.0796 & 0.0642 & 0.0647 & 0.1007 & 0.0522 & 0.0812 \\
\hline 6.4years-.0391 & 0.0948 & 0.0783 & 0.077 & 0.1199 & 0.0636 & 0.0991 \\
\hline 5.33 & 0.0708 & 0.0499 & 0.0576 & 0.0896 & 0.0405 & 0.0631 \\
\hline 4.57 & 0.0439 & 0.0357 & 0.0357 & 0.0555 & 0.029 & 0.0452 \\
\hline 4.00 & 0.0352 & 0.0246 & 0.0286 & 0.0446 & 0.02 & 0.0311 \\
\hline 3.56 & 0.0217 & 0.0178 & 0.0177 & 0.0275 & 0.0145 & 0.0226 \\
\hline 3.2 years-.0781 & 0.0101 & 0.0074 & 0.0082 & 0.0128 & 0.006 & 0.0094 \\
\hline 2.91 & 0.0035 & 0.0016 & 0.0028 & 0.0044 & 0.0013 & 0.002 \\
\hline 2.67 & 0.0070 & 0.0018 & 0.0057 & 0.0088 & 0.0014 & 0.0023 \\
\hline 2.46 & 0.0055 & 0.0011 & 0.0045 & 0.0069 & 0.0009 & 0.0014 \\
\hline 2.29 & 0.0072 & 0.0009 & 0.0059 & 0.0092 & 0.0007 & 0.0011 \\
\hline 2.13years-.117 & 0.0046 & 0.0008 & 0.0038 & 0.0059 & 0.0006 & 0.001 \\
\hline 2.00 & 0.0049 & 0.0005 & 0.004 & 0.0062 & 0.0004 & 0.0006 \\
\hline 1.88 & 0.0029 & 0.0005 & 0.0024 & 0.0037 & 0.0004 & 0.0006 \\
\hline 1.78 & 0.0019 & 0.0013 & 0.0016 & 0.0025 & 0.0011 & 0.0017 \\
\hline 1.68 & 0.0017 & 0.0011 & 0.0014 & 0.0021 & 0.0009 & 0.0014 \\
\hline 1.6years-.156 & 0.0014 & 0.0032 & 0.0012 & 0.0018 & 0.0026 & 0.0041 \\
\hline 1.52 & 0.0057 & 0.0023 & 0.0047 & 0.0073 & 0.0019 & 0.003 \\
\hline 1.45 & 0.0071 & 0.0023 & 0.0058 & 0.009 & 0.0019 & 0.0029 \\
\hline 1.39 & 0.0115 & 0.0004 & 0.0094 & 0.0146 & 0.0003 & 0.0005 \\
\hline 1.33 & 0.0076 & 0.0027 & 0.0062 & 0.0096 & 0.0022 & 0.0034 \\
\hline 1.28years-.195 & 0.0064 & 0.0042 & 0.0052 & 0.0081 & 0.0034 & 0.0053 \\
\hline 1.23 & 0.0028 & 0.0042 & 0.0022 & 0.0035 & 0.0034 & 0.0053 \\
\hline 1.19 & 0.0025 & 0.0020 & 0.0021 & 0.0032 & 0.0016 & 0.0025 \\
\hline 1.14 & 0.0022 & 0.0011 & 0.0018 & 0.0028 & 0.0009 & 0.0014 \\
\hline 1.10 & 0.0019 & 0.0009 & 0.0016 & 0.0024 & 0.0008 & 0.0012 \\
\hline 1.07years-.234 & 0.0048 & 0.0035 & 0.0039 & 0.006 & 0.0028 & 0.0044 \\
\hline 1.03 & 0.0098 & 0.0040 & 0.008 & 0.0124 & 0.0032 & 0.005 \\
\hline 1.00 & 0.0097 & 0.0043 & 0.0079 & 0.0123 & 0.0035 & 0.0055 \\
\hline 11.64 & 0.0063 & 0.0051 & 0.0051 & 0.008 & 0.0041 & 0.0064 \\
\hline 11.29 & 0.0016 & 0.0060 & 0.0013 & 0.002 & 0.0049 & 0.0076 \\
\hline 11months-.273 & 0.0015 & 0.0057 & 0.0012 & 0.0019 & 0.0046 & 0.0072 \\
\hline 10.67 & 0.0025 & 0.0026 & 0.002 & 0.0031 & 0.0021 & 0.0033 \\
\hline 10.38 & 0.0019 & 0.0009 & 0.0016 & 0.0024 & 0.0007 & 0.0012 \\
\hline 10.11 & 0.0021 & 0.0021 & 0.0017 & 0.0026 & 0.0017 & 0.0026 \\
\hline 9.85 & 0.0019 & 0.0033 & 0.0016 & 0.0024 & 0.0027 & 0.0041 \\
\hline 9.6months-.312 & 0.0024 & 0.0041 & 0.0019 & 0.003 & 0.0033 & 0.0052 \\
\hline 9.37 & 0.0023 & 0.0028 & 0.0019 & 0.0029 & 0.0023 & 0.0036 \\
\hline 9.14 & 0.0015 & 0.0015 & 0.0012 & 0.0019 & 0.0012 & 0.0019 \\
\hline 8.93 & 0.0024 & 0.0007 & 0.002 & 0.0031 & 0.0005 & 0.0008 \\
\hline 8.73 & 0.0042 & 0.0010 & 0.0034 & 0.0054 & 0.0008 & 0.0012 \\
\hline 8.53months-..352 & 0.0053 & 0.0013 & 0.0043 & 0.0067 & 0.001 & 0.0016 \\
\hline 8.35 & 0.0041 & 0.0013 & 0.0033 & 0.0052 & 0.001 & 0.0016 \\
\hline 8.17 & 0.0016 & 0.0013 & 0.0013 & 0.0021 & 0.001 & 0.0016 \\
\hline 8.00 & 0.0008 & 0.0013 & 0.0007 & 0.0011 & 0.0011 & 0.0016 \\
\hline 7.84 & 0.0009 & 0.0027 & 0.0007 & 0.0011 & 0.0022 & 0.0034 \\
\hline 7.68months-..39 & 0.0022 & 0.0023 & 0.0018 & 0.0028 & 0.0019 & 0.003 \\
\hline 7.53 & 0.0028 & 0.0019 & 0.0023 & 0.0035 & 0.0015 & 0.0024 \\
\hline 7.38 & 0.0026 & 0.0003 & 0.0021 & 0.0033 & 0.0003 & 0.0004 \\
\hline 7.25 & 0.0016 & 0.0003 & 0.0013 & 0.002 & 0.0003 & 0.0004 \\
\hline 7.11 & 0.0020 & 0.0008 & 0.0016 & 0.0025 & 0.0006 & 0.001 \\
\hline 6.98months-.43 & 0.0047 & 0.0010 & 0.0038 & 0.0059 & 0.0008 & 0.0013 \\
\hline 6.86 & 0.0090 & 0.0015 & 0.0073 & 0.0114 & 0.0012 & 0.0019 \\
\hline
\end{tabular}




\begin{tabular}{|rr|rr|rrrr|} 
& $\mathbf{6 . 7 4}$ & $\mathbf{0 . 0 0 9 4}$ & 0.0011 & 0.0077 & 0.0119 & 0.0009 & 0.0014 \\
& $\mathbf{6 . 6 2}$ & $\mathbf{0 . 0 0 9 3}$ & 0.0012 & 0.0075 & 0.0117 & 0.001 & 0.0015 \\
& $\mathbf{6 . 5 1}$ & $\mathbf{0 . 0 0 5 3}$ & 0.0018 & 0.0043 & 0.0068 & 0.0014 & 0.0022 \\
$\mathbf{6 . 4 m o n t h s - . 4 6}$ & & $\mathbf{0 . 0 0 3 6}$ & 0.0023 & 0.003 & 0.0046 & 0.0019 & 0.0029 \\
& $\mathbf{6 . 3 0}$ & 0.0011 & $\mathbf{0 . 0 0 2 2}$ & 0.0009 & 0.0014 & 0.0018 & 0.0028 \\
& $\mathbf{6 . 1 9}$ & 0.0010 & $\mathbf{0 . 0 0 1 7}$ & 0.0008 & 0.0013 & 0.0014 & 0.0022 \\
& $\mathbf{6 . 1 0}$ & $\mathbf{0 . 0 0 4 2}$ & 0.0011 & 0.0034 & 0.0053 & 0.0009 & 0.0014 \\
& $\mathbf{6 . 0 0}$ & $\mathbf{0 . 0 0 4 8}$ & 0.0013 & 0.0039 & 0.0061 & 0.0011 & 0.0016 \\
\hline
\end{tabular}

Those in bold are significantly above than the other spectrum value.

Table a5 Power Spectra with 95\% confidence interval limits, Cork 


\begin{tabular}{|c|c|c|c|c|c|c|}
\hline \multirow{2}{*}{\begin{tabular}{r}
\multicolumn{2}{c}{ Periodicity } \\
Time Years/ Months \\
Rads
\end{tabular}} & \multicolumn{2}{|c|}{ Power Spectrum } & \multicolumn{2}{|c|}{ 2nd hand } & \multicolumn{2}{|c|}{ New } \\
\hline & 2nd hand & New & $\begin{array}{l}\text { Lower } \\
\text { CIL }\end{array}$ & $\begin{array}{l}\text { Upper } \\
\text { CIL }\end{array}$ & $\begin{array}{c}\text { Lower } \\
\text { CIL }\end{array}$ & $\begin{array}{l}\text { Upper } \\
\text { CIL }\end{array}$ \\
\hline$\infty-0$ & 0.0021 & 0.0010 & 0.0017 & 0.0026 & 0.0009 & 0.0013 \\
\hline 32.00 & 0.0024 & 0.0009 & 0.0019 & 0.0030 & 0.0007 & 0.0011 \\
\hline 16.00 & 0.0068 & 0.0029 & 0.0055 & 0.0086 & 0.0024 & 0.0037 \\
\hline 10.67 & 0.0398 & 0.0301 & 0.0323 & 0.0503 & 0.0245 & 0.0381 \\
\hline 8.00 & 0.0491 & 0.0457 & 0.0399 & 0.0621 & 0.0371 & 0.0578 \\
\hline 6.4years-.0391 & 0.0523 & 0.0636 & 0.0425 & 0.0662 & 0.0517 & 0.0805 \\
\hline 5.33 & 0.0273 & 0.0502 & 0.0222 & 0.0345 & 0.0408 & 0.0635 \\
\hline 4.57 & 0.0199 & 0.0389 & 0.0162 & 0.0252 & 0.0316 & 0.0492 \\
\hline 4.00 & 0.0276 & 0.0236 & 0.0224 & 0.0349 & 0.0192 & 0.0298 \\
\hline 3.56 & 0.0187 & 0.0101 & 0.0152 & 0.0236 & 0.0082 & 0.0127 \\
\hline 3.2 years-.0781 & 0.0202 & 0.0131 & 0.0164 & 0.0256 & 0.0106 & 0.0165 \\
\hline 2.91 & 0.0056 & 0.0113 & 0.0046 & 0.0071 & 0.0092 & 0.0143 \\
\hline 2.67 & 0.0172 & 0.0155 & 0.014 & 0.0218 & 0.0126 & 0.0196 \\
\hline 2.46 & 0.0126 & 0.0112 & 0.0103 & 0.016 & 0.0091 & 0.0142 \\
\hline 2.29 & 0.0122 & 0.0114 & 0.0099 & 0.0154 & 0.0093 & 0.0145 \\
\hline 2.13years-.117 & 0.0018 & 0.0072 & 0.0015 & 0.0023 & 0.0058 & 0.0091 \\
\hline 2.00 & 0.0025 & 0.0048 & 0.002 & 0.0031 & 0.0039 & 0.006 \\
\hline 1.88 & 0.0028 & 0.0049 & 0.0022 & 0.0035 & 0.004 & 0.0062 \\
\hline 1.78 & 0.0022 & 0.0053 & 0.0018 & 0.0027 & 0.0043 & 0.0067 \\
\hline 1.68 & 0.0022 & 0.0048 & 0.0018 & 0.0028 & 0.0039 & 0.006 \\
\hline 1.6years-.156 & 0.0037 & 0.0042 & 0.003 & 0.0047 & 0.0034 & 0.0053 \\
\hline 1.52 & 0.0043 & 0.0077 & 0.0035 & 0.0055 & 0.0063 & 0.0098 \\
\hline 1.45 & 0.0057 & 0.0098 & 0.0047 & 0.0073 & 0.008 & 0.0125 \\
\hline 1.39 & 0.0060 & 0.0118 & 0.0049 & 0.0076 & 0.0096 & 0.0149 \\
\hline 1.33 & 0.0061 & 0.0099 & 0.0049 & 0.0077 & 0.0081 & 0.0125 \\
\hline 1.28years-.195 & 0.0057 & 0.0079 & 0.0046 & 0.0072 & 0.0064 & 0.01 \\
\hline 1.23 & 0.0041 & 0.0043 & 0.0034 & 0.0052 & 0.0035 & 0.0054 \\
\hline 1.19 & 0.0031 & 0.0051 & 0.0025 & 0.004 & 0.0041 & 0.0064 \\
\hline 1.14 & 0.0029 & 0.0049 & 0.0024 & 0.0037 & 0.004 & 0.0063 \\
\hline 1.10 & 0.0025 & 0.0055 & 0.0021 & 0.0032 & 0.0045 & 0.007 \\
\hline 1.07years-.234 & 0.0103 & 0.0045 & 0.0084 & 0.0131 & 0.0036 & 0.0057 \\
\hline 1.03 & 0.0095 & 0.0044 & 0.0077 & 0.012 & 0.0036 & 0.0056 \\
\hline 1.00 & 0.0095 & 0.0032 & 0.0077 & 0.012 & 0.0026 & 0.004 \\
\hline 11.64 & 0.0014 & 0.0017 & 0.0011 & 0.0018 & 0.0014 & 0.0022 \\
\hline 11.29 & 0.0005 & 0.0024 & 0.0004 & 0.0007 & 0.0019 & 0.003 \\
\hline 11months-.273 & 0.0039 & 0.0032 & 0.0032 & 0.005 & 0.0026 & 0.004 \\
\hline 10.67 & 0.0038 & 0.0029 & 0.0031 & 0.0048 & 0.0023 & 0.0036 \\
\hline 10.38 & 0.0048 & 0.0020 & 0.0039 & 0.006 & 0.0017 & 0.0026 \\
\hline 10.11 & 0.0012 & 0.0024 & 0.001 & 0.0015 & 0.0019 & 0.003 \\
\hline 9.85 & 0.0019 & 0.0030 & 0.0016 & 0.0024 & 0.0024 & 0.0038 \\
\hline 9.6months-.312 & 0.0021 & 0.0045 & 0.0017 & 0.0026 & 0.0037 & 0.0057 \\
\hline 9.37 & 0.0023 & 0.0042 & 0.0019 & 0.003 & 0.0034 & 0.0053 \\
\hline 9.14 & 0.0018 & 0.0040 & 0.0015 & 0.0023 & 0.0032 & 0.005 \\
\hline 8.93 & 0.0016 & 0.0043 & 0.0013 & 0.002 & 0.0035 & 0.0054 \\
\hline 8.73 & 0.0032 & 0.0035 & 0.0026 & 0.004 & 0.0028 & 0.0044 \\
\hline 8.53months-..352 & 0.0030 & 0.0029 & 0.0024 & 0.0038 & 0.0024 & 0.0037 \\
\hline 8.35 & 0.0023 & 0.0030 & 0.0018 & 0.0028 & 0.0024 & 0.0038 \\
\hline 8.17 & 0.0004 & 0.0045 & 0.0003 & 0.0005 & 0.0036 & 0.0057 \\
\hline 8.00 & 0.0005 & 0.0063 & 0.0004 & 0.0007 & 0.0052 & 0.008 \\
\hline 7.84 & 0.0011 & 0.0053 & 0.0009 & 0.0014 & 0.0043 & 0.0067 \\
\hline 7.68months-.39 & 0.0023 & 0.0035 & 0.0019 & 0.0029 & 0.0028 & 0.0044 \\
\hline 7.53 & 0.0033 & 0.0015 & 0.0026 & 0.0041 & 0.0012 & 0.0019 \\
\hline 7.38 & 0.0031 & 0.0007 & 0.0025 & 0.0039 & 0.0006 & 0.0009 \\
\hline 7.25 & 0.0019 & 0.0029 & 0.0015 & 0.0023 & 0.0024 & 0.0037 \\
\hline 7.11 & 0.0013 & 0.0054 & 0.0011 & 0.0017 & 0.0044 & 0.0069 \\
\hline 6.98months-.43 & 0.0066 & 0.0058 & 0.0053 & 0.0083 & 0.0047 & 0.0073 \\
\hline 6.86 & 0.0070 & 0.0048 & 0.0057 & 0.0088 & 0.0039 & 0.0061 \\
\hline
\end{tabular}




\begin{tabular}{|rr|rr|rrrr|} 
& $\mathbf{6 . 7 4}$ & $\mathbf{0 . 0 0 7 4}$ & 0.0022 & 0.006 & 0.0093 & 0.0018 & 0.0028 \\
& $\mathbf{6 . 6 2}$ & $\mathbf{0 . 0 0 5 0}$ & 0.0021 & 0.0041 & 0.0063 & 0.0017 & 0.0027 \\
& $\mathbf{6 . 5 1}$ & $\mathbf{0 . 0 0 5 1}$ & 0.0021 & 0.0041 & 0.0064 & 0.0017 & 0.0027 \\
6.4months-.46 & & $\mathbf{0 . 0 0 4 3}$ & 0.0026 & 0.0035 & 0.0055 & 0.0022 & 0.0033 \\
& $\mathbf{6 . 3 0}$ & 0.0037 & 0.0024 & 0.003 & 0.0047 & 0.002 & 0.003 \\
& $\mathbf{6 . 1 9}$ & $\mathbf{0 . 0 0 4 4}$ & 0.0025 & 0.0035 & 0.0055 & 0.002 & 0.0032 \\
& $\mathbf{6 . 1 0}$ & 0.0041 & 0.0036 & 0.0034 & 0.0052 & 0.0029 & 0.0046 \\
& $\mathbf{6 . 0 0}$ & 0.0026 & $\mathbf{0 . 0 0 4 7}$ & 0.0021 & 0.0033 & 0.0039 & 0.006 \\
\hline
\end{tabular}

Those in bold are significantly above than the other spectrum value.

Table a6 Power Spectra with 95\% confidence interval limits, Limerick 


\begin{tabular}{|c|c|c|c|c|c|c|}
\hline \multirow{2}{*}{\begin{tabular}{r}
\multicolumn{2}{c}{ Periodicity } \\
Time Years/ Months \\
Rads
\end{tabular}} & \multicolumn{2}{|c|}{ Power Spectrum } & \multicolumn{2}{|c|}{ 2nd hand } & \multicolumn{2}{|c|}{ New } \\
\hline & 2nd hand & New & $\begin{array}{l}\text { Lower } \\
\text { CIL }\end{array}$ & $\begin{array}{l}\text { Upper } \\
\text { CIL }\end{array}$ & $\begin{array}{l}\text { Lower } \\
\text { CIL }\end{array}$ & $\begin{array}{l}\text { Upper } \\
\text { CIL }\end{array}$ \\
\hline$\infty-0$ & 0.0011 & 0.0006 & 0.0009 & 0.0014 & 0.0005 & 0.0008 \\
\hline 32.00 & 0.0026 & 0.0010 & 0.0021 & 0.0033 & 0.0008 & 0.0013 \\
\hline 16.00 & 0.0048 & 0.0074 & 0.0039 & 0.0061 & 0.006 & 0.0094 \\
\hline 10.67 & 0.0441 & 0.0449 & 0.0358 & 0.0557 & 0.0365 & 0.0569 \\
\hline 8.00 & 0.0456 & 0.0470 & 0.0371 & 0.0577 & 0.0382 & 0.0594 \\
\hline 6.4years-.0391 & 0.0456 & 0.0469 & 0.0371 & 0.0577 & 0.0381 & 0.0593 \\
\hline 5.33 & 0.0176 & 0.0116 & 0.0143 & 0.0223 & 0.0094 & 0.0147 \\
\hline 4.57 & 0.0143 & 0.0090 & 0.0116 & 0.0181 & 0.0073 & 0.0113 \\
\hline 4.00 & 0.0260 & 0.0211 & 0.0211 & 0.0328 & 0.0171 & 0.0267 \\
\hline 3.56 & 0.0182 & 0.0213 & 0.0148 & 0.0231 & 0.0174 & 0.027 \\
\hline 3.2 years-.0781 & 0.0213 & 0.0220 & 0.0173 & 0.027 & 0.0179 & 0.0278 \\
\hline 2.91 & 0.0122 & 0.0152 & 0.0099 & 0.0154 & 0.0123 & 0.0192 \\
\hline 2.67 & 0.0280 & 0.0154 & 0.0228 & 0.0354 & 0.0126 & 0.0195 \\
\hline 2.46 & 0.0257 & 0.0191 & 0.0209 & 0.0325 & 0.0155 & 0.0241 \\
\hline 2.29 & 0.0215 & 0.0091 & 0.0175 & 0.0273 & 0.0074 & 0.0115 \\
\hline 2.13years-.117 & 0.0025 & 0.0069 & 0.002 & 0.0032 & 0.0056 & 0.0088 \\
\hline 2.00 & 0.0055 & 0.0049 & 0.0045 & 0.007 & 0.004 & 0.0062 \\
\hline 1.88 & 0.0069 & 0.0040 & 0.0056 & 0.0087 & 0.0032 & 0.005 \\
\hline 1.78 & 0.0069 & 0.0036 & 0.0056 & 0.0087 & 0.0029 & 0.0046 \\
\hline 1.68 & 0.0057 & 0.0013 & 0.0046 & 0.0072 & 0.0011 & 0.0017 \\
\hline 1.6years-.156 & 0.0040 & 0.0014 & 0.0033 & 0.0051 & 0.0011 & 0.0017 \\
\hline 1.52 & 0.0042 & 0.0029 & 0.0034 & 0.0053 & 0.0024 & 0.0037 \\
\hline 1.45 & 0.0028 & 0.0034 & 0.0023 & 0.0036 & 0.0028 & 0.0044 \\
\hline 1.39 & 0.0039 & 0.0033 & 0.0032 & 0.005 & 0.0027 & 0.0042 \\
\hline 1.33 & 0.0051 & 0.0025 & 0.0041 & 0.0064 & 0.002 & 0.0031 \\
\hline 1.28years-.195 & 0.0068 & 0.0020 & 0.0055 & 0.0086 & 0.0016 & 0.0025 \\
\hline 1.23 & 0.0061 & 0.0045 & 0.005 & 0.0077 & 0.0036 & 0.0057 \\
\hline 1.19 & 0.0039 & 0.0050 & 0.0032 & 0.005 & 0.0041 & 0.0063 \\
\hline 1.14 & 0.0027 & 0.0096 & 0.0022 & 0.0034 & 0.0078 & 0.0122 \\
\hline 1.10 & 0.0027 & 0.0069 & 0.0022 & 0.0034 & 0.0056 & 0.0087 \\
\hline 1.07years-.234 & 0.0049 & 0.0095 & 0.004 & 0.0063 & 0.0077 & 0.012 \\
\hline 1.03 & 0.0029 & 0.0049 & 0.0024 & 0.0037 & 0.004 & 0.0062 \\
\hline 1.00 & 0.0024 & 0.0063 & 0.0019 & 0.003 & 0.0051 & 0.008 \\
\hline 11.64 & 0.0007 & 0.0020 & 0.0006 & 0.0009 & 0.0016 & 0.0025 \\
\hline 11.29 & 0.0020 & 0.0023 & 0.0016 & 0.0025 & 0.0019 & 0.0029 \\
\hline 11months-.273 & 0.0028 & 0.0007 & 0.0023 & 0.0035 & 0.0006 & 0.0009 \\
\hline 10.67 & 0.0027 & 0.0008 & 0.0022 & 0.0034 & 0.0006 & 0.001 \\
\hline 10.38 & 0.0020 & 0.0004 & 0.0016 & 0.0025 & 0.0003 & 0.0005 \\
\hline 10.11 & 0.0024 & 0.0009 & 0.0019 & 0.003 & 0.0007 & 0.0011 \\
\hline 9.85 & 0.0036 & 0.0020 & 0.0029 & 0.0045 & 0.0016 & 0.0025 \\
\hline 9.6months-.312 & 0.0079 & 0.0058 & 0.0064 & 0.01 & 0.0047 & 0.0074 \\
\hline 9.37 & 0.0105 & 0.0053 & 0.0085 & 0.0133 & 0.0043 & 0.0067 \\
\hline 9.14 & 0.0115 & 0.0045 & 0.0094 & 0.0146 & 0.0037 & 0.0057 \\
\hline 8.93 & 0.0067 & 0.0009 & 0.0055 & 0.0085 & 0.0008 & 0.0012 \\
\hline 8.73 & 0.0054 & 0.0022 & 0.0044 & 0.0069 & 0.0018 & 0.0027 \\
\hline 8.53months-..352 & 0.0028 & 0.0020 & 0.0023 & 0.0036 & 0.0016 & 0.0026 \\
\hline 8.35 & 0.0032 & 0.0030 & 0.0026 & 0.004 & 0.0024 & 0.0038 \\
\hline 8.17 & 0.0015 & 0.0041 & 0.0012 & 0.0019 & 0.0033 & 0.0052 \\
\hline 8.00 & 0.0016 & 0.0040 & 0.0013 & 0.002 & 0.0033 & 0.0051 \\
\hline 7.84 & 0.0031 & 0.0028 & 0.0026 & 0.004 & 0.0023 & 0.0035 \\
\hline 7.68months-..39 & 0.0055 & 0.0016 & 0.0045 & 0.007 & 0.0013 & 0.0021 \\
\hline 7.53 & 0.0075 & 0.0014 & 0.0061 & 0.0095 & 0.0012 & 0.0018 \\
\hline 7.38 & 0.0088 & 0.0028 & 0.0072 & 0.0112 & 0.0022 & 0.0035 \\
\hline 7.25 & 0.0059 & 0.0018 & 0.0048 & 0.0075 & 0.0014 & 0.0023 \\
\hline 7.11 & 0.0061 & 0.0023 & 0.0049 & 0.0077 & 0.0018 & 0.0029 \\
\hline 6.98months-.43 & 0.0044 & 0.0014 & 0.0036 & 0.0056 & 0.0012 & 0.0018 \\
\hline 6.86 & 0.0045 & 0.0022 & 0.0036 & 0.0057 & 0.0017 & 0.0027 \\
\hline
\end{tabular}




\begin{tabular}{|rr|rr|rrrr|} 
& $\mathbf{6 . 7 4}$ & $\mathbf{0 . 0 0 4 7}$ & 0.0026 & 0.0038 & 0.0059 & 0.0021 & 0.0033 \\
& $\mathbf{6 . 6 2}$ & $\mathbf{0 . 0 0 4 6}$ & 0.0023 & 0.0037 & 0.0058 & 0.0019 & 0.003 \\
& $\mathbf{6 . 5 1}$ & $\mathbf{0 . 0 0 4 9}$ & 0.0026 & 0.004 & 0.0063 & 0.0021 & 0.0033 \\
6.4months-.46 & & 0.0031 & 0.0029 & 0.0025 & 0.0039 & 0.0023 & 0.0036 \\
& $\mathbf{6 . 3 0}$ & 0.0018 & 0.0027 & 0.0015 & 0.0023 & 0.0022 & 0.0034 \\
& $\mathbf{6 . 1 9}$ & 0.0015 & 0.0016 & 0.0012 & 0.0019 & 0.0013 & 0.0021 \\
$\mathbf{6 . 1 0}$ & $\mathbf{0 . 0 0 3 7}$ & 0.0003 & 0.003 & 0.0047 & 0.0003 & 0.0004 \\
& $\mathbf{6 . 0 0}$ & $\mathbf{0 . 0 0 3 7}$ & 0.0006 & 0.003 & 0.0047 & 0.0005 & 0.0007 \\
\hline
\end{tabular}

Those in bold are significantly above than the other spectrum value.

Table a7 Power Spectra with $95 \%$ confidence interval limits, Galway 


\begin{tabular}{|c|c|c|c|c|c|c|}
\hline Periodicity & \multicolumn{2}{|c|}{ Power Spectrum } & \multicolumn{2}{|c|}{ 2nd hand } & \multicolumn{2}{|c|}{ New } \\
\hline $\begin{array}{r}\text { Time Years/ Months } \\
\text { Rads }\end{array}$ & 2nd hand & New & $\begin{array}{l}\text { Lower } \\
\text { CIL }\end{array}$ & $\begin{array}{l}\text { Upper } \\
\text { CIL }\end{array}$ & $\begin{array}{l}\text { Lower } \\
\text { CIL }\end{array}$ & $\begin{array}{l}\text { Upper } \\
\text { CIL }\end{array}$ \\
\hline$\infty-0$ & 0.0015 & 0.0016 & 0.0012 & 0.0019 & 0.0013 & 0.0021 \\
\hline 32.00 & 0.0048 & 0.0010 & 0.0039 & 0.0060 & 0.0008 & 0.0012 \\
\hline 16.00 & 0.0051 & 0.0018 & 0.0042 & 0.0065 & 0.0015 & 0.0023 \\
\hline 10.67 & 0.0320 & 0.0228 & 0.026 & 0.0405 & 0.0186 & 0.0289 \\
\hline 8.00 & 0.0640 & 0.0453 & 0.0521 & 0.081 & 0.0368 & 0.0573 \\
\hline 6.4years-.0391 & 0.0649 & 0.0485 & 0.0528 & 0.0822 & 0.0395 & 0.0614 \\
\hline 5.33 & 0.0465 & 0.0383 & 0.0378 & 0.0588 & 0.0312 & 0.0485 \\
\hline 4.57 & 0.0123 & 0.0266 & 0.01 & 0.0156 & 0.0216 & 0.0337 \\
\hline 4.00 & 0.0133 & 0.0435 & 0.0108 & 0.0168 & 0.0354 & 0.0551 \\
\hline 3.56 & 0.0077 & 0.0319 & 0.0063 & 0.0098 & 0.026 & 0.0404 \\
\hline 3.2 years-.0781 & 0.0089 & 0.0266 & 0.0073 & 0.0113 & 0.0216 & 0.0337 \\
\hline 2.91 & 0.0141 & 0.0058 & 0.0114 & 0.0178 & 0.0048 & 0.0074 \\
\hline 2.67 & 0.0189 & 0.0065 & 0.0153 & 0.0239 & 0.0053 & 0.0082 \\
\hline 2.46 & 0.0213 & 0.0032 & 0.0173 & 0.0269 & 0.0026 & 0.0041 \\
\hline 2.29 & 0.0205 & 0.0035 & 0.0167 & 0.026 & 0.0029 & 0.0045 \\
\hline 2.13years-.117 & 0.0126 & 0.0049 & 0.0103 & 0.016 & 0.004 & 0.0061 \\
\hline 2.00 & 0.0115 & 0.0035 & 0.0094 & 0.0146 & 0.0029 & 0.0045 \\
\hline 1.88 & 0.0050 & 0.0044 & 0.004 & 0.0063 & 0.0036 & 0.0056 \\
\hline 1.78 & 0.0054 & 0.0063 & 0.0044 & 0.0068 & 0.0051 & 0.008 \\
\hline 1.68 & 0.0028 & 0.0082 & 0.0023 & 0.0036 & 0.0067 & 0.0104 \\
\hline 1.6years-.156 & 0.0094 & 0.0098 & 0.0077 & 0.0119 & 0.0079 & 0.0123 \\
\hline 1.52 & 0.0157 & 0.0065 & 0.0127 & 0.0198 & 0.0053 & 0.0082 \\
\hline 1.45 & 0.0161 & 0.0120 & 0.0131 & 0.0204 & 0.0098 & 0.0152 \\
\hline 1.39 & 0.0104 & 0.0098 & 0.0084 & 0.0131 & 0.0079 & 0.0124 \\
\hline 1.33 & 0.0045 & 0.0100 & 0.0037 & 0.0057 & 0.0082 & 0.0127 \\
\hline 1.28years-.195 & 0.0052 & 0.0021 & 0.0042 & 0.0066 & 0.0017 & 0.0027 \\
\hline 1.23 & 0.0098 & 0.0018 & 0.0079 & 0.0124 & 0.0015 & 0.0023 \\
\hline 1.19 & 0.0200 & 0.0044 & 0.0163 & 0.0253 & 0.0036 & 0.0056 \\
\hline 1.14 & 0.0193 & 0.0076 & 0.0157 & 0.0244 & 0.0062 & 0.0096 \\
\hline 1.10 & 0.0215 & 0.0081 & 0.0174 & 0.0271 & 0.0066 & 0.0103 \\
\hline 1.07years-.234 & 0.0148 & 0.0066 & 0.012 & 0.0187 & 0.0054 & 0.0084 \\
\hline 1.03 & 0.0161 & 0.0039 & 0.0131 & 0.0204 & 0.0032 & 0.0049 \\
\hline 1.00 & 0.0112 & 0.0039 & 0.0091 & 0.0142 & 0.0031 & 0.0049 \\
\hline 11.64 & 0.0064 & 0.0057 & 0.0052 & 0.0081 & 0.0046 & 0.0072 \\
\hline 11.29 & 0.0036 & 0.0062 & 0.0029 & 0.0045 & 0.005 & 0.0079 \\
\hline 11months-.273 & 0.0023 & 0.0084 & 0.0019 & 0.003 & 0.0068 & 0.0106 \\
\hline 10.67 & 0.0024 & 0.0052 & 0.0019 & 0.003 & 0.0042 & 0.0066 \\
\hline 10.38 & 0.0028 & 0.0061 & 0.0023 & 0.0035 & 0.005 & 0.0078 \\
\hline 10.11 & 0.0018 & 0.0066 & 0.0015 & 0.0023 & 0.0053 & 0.0083 \\
\hline 9.85 & 0.0017 & 0.0082 & 0.0014 & 0.0021 & 0.0067 & 0.0104 \\
\hline 9.6months-.312 & 0.0017 & 0.0061 & 0.0014 & 0.0021 & 0.0049 & 0.0077 \\
\hline 9.37 & 0.0016 & 0.0033 & 0.0013 & 0.0021 & 0.0027 & 0.0042 \\
\hline 9.14 & 0.0027 & 0.0025 & 0.0022 & 0.0034 & 0.002 & 0.0031 \\
\hline 8.93 & 0.0022 & 0.0043 & 0.0018 & 0.0028 & 0.0035 & 0.0054 \\
\hline 8.73 & 0.0031 & 0.0052 & 0.0025 & 0.0039 & 0.0043 & 0.0066 \\
\hline 8.53months-..352 & 0.0047 & 0.0050 & 0.0039 & 0.006 & 0.0041 & 0.0063 \\
\hline 8.35 & 0.0045 & 0.0045 & 0.0036 & 0.0057 & 0.0037 & 0.0057 \\
\hline 8.17 & 0.0046 & 0.0035 & 0.0038 & 0.0059 & 0.0028 & 0.0044 \\
\hline 8.00 & 0.0027 & 0.0031 & 0.0022 & 0.0034 & 0.0025 & 0.0039 \\
\hline 7.84 & 0.0034 & 0.0021 & 0.0028 & 0.0044 & 0.0017 & 0.0027 \\
\hline 7.68months-..39 & 0.0036 & 0.0033 & 0.0029 & 0.0046 & 0.0027 & 0.0042 \\
\hline 7.53 & 0.0041 & 0.0031 & 0.0033 & 0.0052 & 0.0026 & 0.004 \\
\hline 7.38 & 0.0038 & 0.0030 & 0.0031 & 0.0047 & 0.0025 & 0.0038 \\
\hline 7.25 & 0.0024 & 0.0012 & 0.002 & 0.0031 & 0.001 & 0.0016 \\
\hline 7.11 & 0.0017 & 0.0018 & 0.0014 & 0.0021 & 0.0015 & 0.0023 \\
\hline 6.98months-.43 & 0.0019 & 0.0022 & 0.0016 & 0.0025 & 0.0017 & 0.0027 \\
\hline 6.86 & 0.0034 & 0.0032 & 0.0027 & 0.0043 & 0.0026 & 0.004 \\
\hline
\end{tabular}




\begin{tabular}{|rr|rr|rrrr|} 
& $\mathbf{6 . 7 4}$ & $\mathbf{0 . 0 0 6 7}$ & 0.0034 & 0.0054 & 0.0085 & 0.0027 & 0.0043 \\
& $\mathbf{6 . 6 2}$ & $\mathbf{0 . 0 1 2 8}$ & 0.0026 & 0.0104 & 0.0163 & 0.0021 & 0.0033 \\
& $\mathbf{6 . 5 1}$ & $\mathbf{0 . 0 1 4 1}$ & 0.0019 & 0.0114 & 0.0178 & 0.0016 & 0.0025 \\
6.4months-.46 & & $\mathbf{0 . 0 1 2 9}$ & 0.0006 & 0.0105 & 0.0163 & 0.0005 & 0.0007 \\
& $\mathbf{6 . 3 0}$ & 0.0059 & 0.0042 & 0.0048 & 0.0074 & 0.0034 & 0.0053 \\
& $\mathbf{6 . 1 9}$ & 0.0036 & 0.0043 & 0.0029 & 0.0046 & 0.0035 & 0.0055 \\
& $\mathbf{6 . 1 0}$ & 0.0010 & $\mathbf{0 . 0 0 5 6}$ & 0.0008 & 0.0012 & 0.0046 & 0.0071 \\
& $\mathbf{6 . 0 0}$ & 0.0014 & $\mathbf{0 . 0 0 2 6}$ & 0.0012 & 0.0018 & 0.0021 & 0.0033 \\
\hline
\end{tabular}

Those in bold are significantly above than the other spectrum value.

Table a8 Power Spectra with $95 \%$ confidence interval limits, Waterford 
${ }^{\text {i }}$ For a snapshot of Ireland's housing situation, one could turn to the Census, (2002) and the Annual Housing Statistics Bulletin (DoELG, 2002). 